\title{
-Comparison of Satellite, Model, and In Situ Values of Photosynthetically Available Radiation (PAR)
}

\author{
Richard W. Gould Jr., Dong S. Ko, SHerwin D. LAdner, And T. AdAm Lawson \\ Oceanography Division, Naval Research Laboratory, Stennis Space Center, Mississippi \\ Clinton P. MacDonald \\ Meteorology, Measurements, and Outreach, Sonoma Technology, Inc., Petaluma, California
}

(Manuscript received 15 June 2018, in final form 25 January 2019)

\begin{abstract}
Photosynthetically available radiation (PAR) incident at the sea surface penetrates into the water column and drives oceanic primary production. Ecosystem models to estimate phytoplankton biomass and primary production require an estimate of sea surface PAR, which is available from satellite ocean color imagery and atmospheric model predictions. Because the PAR values could come from either source, it is important to understand the variability and accuracies of each. We performed spatial and temporal analyses covering multiple years and seasons, and clear/cloudy conditions. We compare values derived from the imagery to those from the models and to in situ measurements in the Gulf of Mexico to validate the imagery and models and to assess PAR variability based on source. Averaged over space or time, the relative errors in PAR between the six sources (two satellite, three model, and in situ) are generally less than $5 \%-7 \%$, but they can vary up to $11 \%$. However, the errors and biases on a daily or pixel-by-pixel basis are larger, and the averages can mask seasonal trends.
\end{abstract}

\section{Introduction}

The magnitude and distribution of solar radiation incident at the sea surface impacts the physics, chemistry, and biology of the ocean. From a physical perspective, it penetrates into the water column and heats the upper layer of the ocean, driving stratification and thermohaline circulation, and through ocean-atmosphere coupling and feedback mechanisms influences air/sea heat exchange, winds, and climate. Solar radiation also affects the partitioning of organic matter between particulate and dissolved phases (Shank et al. 2011), as well as the chemical speciation of the dissolved material through oxidative process, such as the photodegradation of chromophoric dissolved organic matter (CDOM; Zhang et al. 2009).

\footnotetext{
Denotes content that is immediately available upon publica-
} tion as open access.

Corresponding author: Richard W. Gould Jr., richard.gould@ nrlssc.navy.mil
Biologically, a portion of the shortwave radiation, the photosynthetically available radiation (PAR), drives land and oceanic primary production (Campbell et al. 2002; Carr et al. 2006; Mercado et al. 2009; Platt 1986). Accurate estimates of sea surface PAR (and its attenuation with depth) are required as input to ecosystem models, to derive accurate estimates of phytoplankton biomass and primary production from ocean color (Friedrichs et al. 2009; Frouin et al. 2018; Saux Picart et al. 2014). Too much light can lead to photooxidation of phytoplankton pigments and photoinhibition (Long et al. 1994; Nelson 1993; Platt et al. 1980). Biological production and optically active constituents of the water column absorb light, which serves to trap heat in the surface layer, impacting water column density, mixed layer thickness, and even precipitation patterns (Edwards et al. 2004; Gildor et al. 2003; Jolliff et al. 2012; Lewis et al. 1983; Nakamoto et al. 2000; Sathyendranath et al. 1991; Simonot et al. 1988; Zaneveld et al. 1981). Thus, heating of the ocean surface layer occurs both directly by the incident radiation and indirectly by effects through the biology. 
The impetus for this work derives from our efforts to couple a hydrodynamic model with an ecological model to describe oxygen dynamics in the hypoxic zone off the Louisiana coast. We are coupling physical properties from the Navy Coastal Ocean Model (NCOM; Martin 2000) with biogeochemical properties from the Coastal General Ecosystem Model (CGEM; Lehrter et al. 2017). The biogeochemical model (CGEM) uses an estimate of PAR to drive biological production. One goal of this coupling approach is to simulate the effects of various climate forcing scenarios on the magnitude and distribution of primary production on the Louisiana continental shelf (LCS), and ultimately the effects on hypoxia development. One such forcing factor, which will be the focus of this study, is PAR. Other forcing factors include air/water temperature, precipitation, river discharge, nutrient loads, and water column stratification.

Estimates of PAR are available from satellite ocean color imagery and from atmospheric model predictions. Because there are multiple sources of PAR available as input to hydrodynamic and ecological models, an understanding of the differences between the possible input sources is critical before we can assess the impact of PAR variability on primary production and hypoxia.

In addition, although there has been some limited validation of the satellite-derived PAR values from ocean color sensors (SeaWiFS, MODIS, Global Imager; Frouin and Murakami 2007; Frouin et al. 2003, 2012; Laliberté et al. 2016; Somayajula et al. 2018), there has been even less work comparing shortwave radiation values from various atmospheric models to in situ observations or to satellite values (Bouvet et al. 2002; May et al. 2017). We are specifically interested in addressing these shortcomings for Navy atmospheric models that could be used as potential input sources for NCOM and CGEM. Our objectives are to compare in situ measurements of PAR in the Gulf of Mexico to estimates derived from multiple ocean color satellites and multiple atmospheric models, through multiyear time series analyses at individual locations and spatial analyses across satellite images. The satellites we are using include the Moderate Resolution Imaging Spectroradiometer (MODIS) and the Visible Infrared Imaging Radiometer Suite (VIIRS). The models we are using include the Navy Operational Global Atmospheric Prediction System (NOGAPS), the Coupled Ocean-Atmosphere Mesoscale Prediction System (COAMPS), and the Navy Global Environmental Model (NAVGEM).

\section{Methods}

We performed temporal and spatial comparisons of surface PAR values covering multiple years and seasons in the northern Gulf of Mexico (GOM). Datasets are described below. For the temporal analyses, surface PAR values were extracted from the atmospheric models and satellite imagery at each of three station locations over multiple years and compared to coincident ground-based measurements. These analyses include both cloudy and clear-sky conditions. For the spatial comparisons, rather than examining single-point locations with in situ data, we compared satellite and model data over a large expanse of the northern GOM, for nine specific dates (chosen for mostly clear satellite imagery). Figure 1 shows the three locations for the time series analyses, as well as the large region of interest for the spatial analyses. Table 1 shows the dates of the spatial comparisons, and the satellite and model datasets available for each date. Note that not all data types are available for all dates. VIIRS was launched on 28 October 2011, but data were not available to the public until April 2012 (Cao et al. 2014). Also, the various atmospheric models have not all been operational for the same time periods. MODIS and VIIRS imagery and all gridded model data from NOGAPS, COAMPS, and NAVGEM were mapped to the same equirectangular projection and same ground resolution $(1 \mathrm{~km})$ for the spatial comparisons, using Environment for Visualizing Images (ENVI) software (Excelis Visual Information Solutions, Inc.). Satellite imager cloud pixels were masked and excluded from these comparisons.

PAR can be expressed in terms of the photon flux density, the moles of photons per unit area per unit time $\left(\right.$ moles $\left.\mathrm{m}^{-2} \mathrm{~s}^{-1}\right)$, or in energy units $\left(\mathrm{W} \mathrm{m}^{-2}\right)$. We follow the energy convention to facilitate comparisons with model-derived shortwave radiation values. PAR can be estimated empirically as a proportion of the total surface shortwave radiation $Q_{\mathrm{Sw}}(350-2500 \mathrm{~nm})$ from the atmospheric models or in situ measurements, although that ratio can vary depending on atmospheric composition (clouds, water vapor content, aerosol optical thickness) and solar zenith angle (Baker and Frouin 1987; Bélanger et al. 2013; Frouin and Pinker 1995; Jitts et al. 1976; Pinker and Laszlo 1992). We estimated this proportionality factor from least squares regression analysis of the MODIS and in situ shortwave radiation datasets in the northern Gulf of Mexico, using the three in situ locations separately and in combination. Based on analysis of just the Terrebonne Bay datasets, the conversion factor was calculated as 0.45 (standard error 0.0024 ). The value was 0.48 (standard error 0.0045 ) for the Southwest Pass dataset and 0.47 (standard error 0.0024) for the Chevron oil platform (see section 2a for description of the in situ data sites). For the three datasets combined, a value of $0.45(n=1089$, standard error $=0.014)$ was calculated, and we used this value 


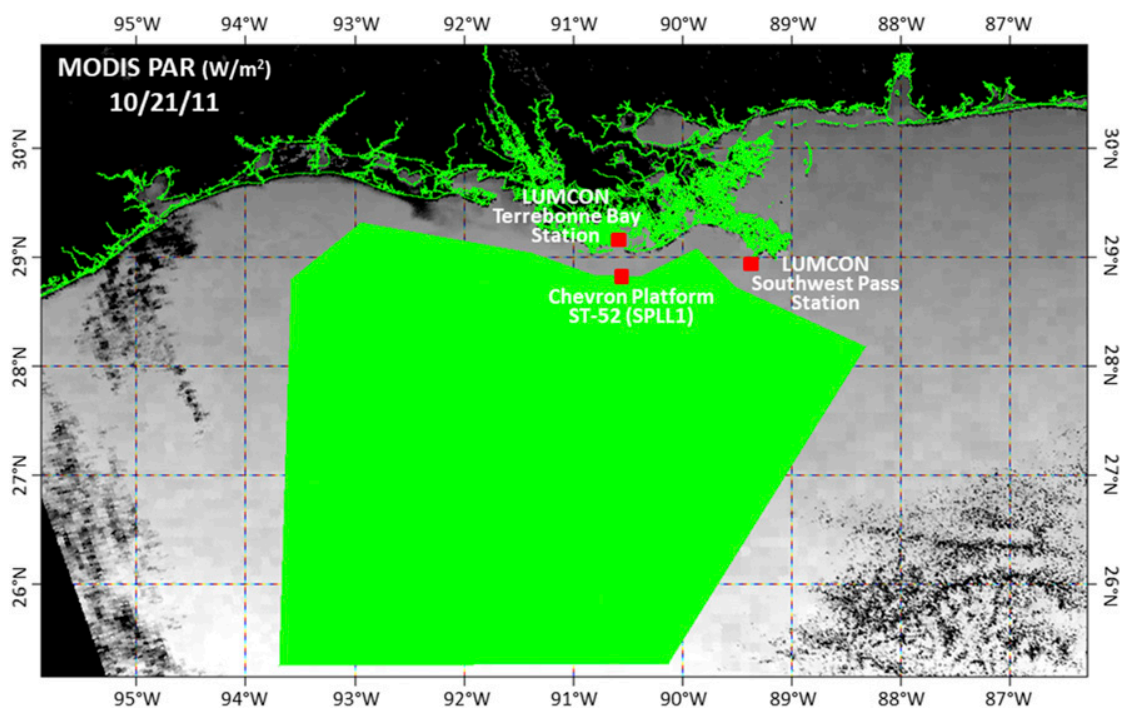

FIG. 1. Ground station locations in the northern GOM for the time series comparisons (red squares). Large region of interest for the spatial comparisons (green polygon). Background image is the MODIS PAR product for 21 Oct 2011.

to convert daily average model and in situ shortwave radiation values $\left(\mathrm{W} \mathrm{m}^{-2}\right)$ to $\mathrm{PAR}\left(\mathrm{W} \mathrm{m}^{-2}\right)$ for the subsequent comparisons:

$$
\operatorname{PAR}\left(\mathrm{W} \mathrm{m}^{-2}\right)=0.45 Q_{\mathrm{SW}} \text {. }
$$

This value is also consistent with literature values (Baker and Frouin 1987; Papaioannou et al. 1993; Pinker and Laszlo 1992). Because we derived the conversion factor from the MODIS and in situ datasets, it is independent of the models used in the comparisons. As mentioned above, this conversion factor can vary depending on atmospheric conditions, but we calculated it based on our regionally specific datasets, which spanned multiple years and seasonal cycles, so we believe it is the best representative value for our study area. Although the conversion factor will affect the magnitude of the relative percent differences in the satellite, model, and in situ comparisons [Eq. (3)], the variability is small, and we applied the conversion factor consistently to minimize impacts, so we do not expect the exact value specified to greatly affect the results, and the summary comparisons will still be valid as well.

\section{a. In situ measurements}

In situ $Q_{\text {sw }}$ measurements were collected at three locations in the northern Gulf of Mexico. Data were collected at two locations by the Louisiana Universities Marine Consortium (LUMCON): Terrebonne Bay $\left(29.1867^{\circ} \mathrm{N}, 90.608^{\circ} \mathrm{W}\right)$ from January 2010 to December 2011 and Southwest Pass $\left(28.9322^{\circ} \mathrm{N}, 89.4069^{\circ} \mathrm{W}\right)$ from January to November 2006 and from January to September 2007. Data were provided by LUMCON as daily averages through a data request to the environmental monitoring group (https://lumcon.edu/environmentalmonitoring/). Additional hourly data were collected by Sonoma Technology, Inc. [under a U.S. Bureau of Ocean Energy Management (BOEM) contract] at a

TABLE 1. Dates, satellite, and model datasets used for the spatial PAR comparisons.

\begin{tabular}{ccccc}
\hline \hline Date & MODIS & VIIRS & NOGAPS & COAMPS \\
\hline 25 Feb 2016 & $\mathrm{X}$ & $\mathrm{X}$ & & NAVGEM \\
10 Feb 2016 & $\mathrm{X}$ & $\mathrm{X}$ & & $\mathrm{X}$ \\
27 Jan 2015 & $\mathrm{X}$ & $\mathrm{X}$ & & $\mathrm{X}$ \\
25 Oct 2014 & $\mathrm{X}$ & $\mathrm{X}$ & & $\mathrm{X}$ \\
22 Jan 2014 & $\mathrm{X}$ & $\mathrm{X}$ & $\mathrm{X}$ & $\mathrm{X}$ \\
4 May 2013 & $\mathrm{X}$ & $\mathrm{X}$ & $\mathrm{X}$ & $\mathrm{X}$ \\
18 Dec 2012 & $\mathrm{X}$ & $\mathrm{X}$ & $\mathrm{X}$ & $\mathrm{X}$ \\
22 Apr 2012 & $\mathrm{X}$ & $\mathrm{X}$ & $\mathrm{X}$ & $\mathrm{X}$ \\
21 Oct 2011 & $\mathrm{X}$ & & & \\
\hline
\end{tabular}


single location: the Chevron oil platform ST-52 $\left(28.867^{\circ} \mathrm{N}\right.$, $90.483^{\circ} \mathrm{W}$ ) from October 2010 to March 2012. Hourly measurements were averaged over $24 \mathrm{~h}$ to obtain daily averages. The measurements and data are described in MacDonald et al. (2013). Daily average data from these three locations were then converted to PAR using Eq. (1).

The LUMCON stations are close to land. The Terrebonne Bay station is located on a fixed water platform about $3-4 \mathrm{~km}$ from land, and the Southwest Pass station is located at the end of a dock. Because satellite PAR estimates are only obtained for water pixels (and the pixels are 1-km resolution), we selected the adjacent water pixel to the Southwest Pass location for the in situ/ satellite comparisons. Because PAR values generally vary minimally over large spatial scales in areas not affected by clouds (at least tens of kilometers, based on examination of ocean color PAR products, author R.W.G. personal observation), we do not expect this small spatial offset to impact results. For the Terrebonne Bay and Chevron oil platform locations, satellite pixel extractions for the comparisons corresponded precisely to the in situ locations. However, PAR measurements collected by a sensor near land can be impacted by land reflectance. Photons reflected by the surface to the atmosphere and backscattered to the surface may not be negligible for a PAR sensor installed over land or at a coastal site. The spherical albedo of the atmosphere is typically 0.2 in the PAR spectral range, and for a surface reflectance of 0.2 , for example, the effect would be an extra flux of about $4 \%$. In addition, the satellitederived PAR values near land can be impacted by an adjacency effect as well (see section 4).

\section{b. Satellite imagery/processing}

Both the VIIRS and MODIS sensors are in sunsynchronous, near-polar orbits. There are two operational MODIS sensors, Terra and Aqua, with morning and afternoon overpasses, respectively, separated in time by about $3 \mathrm{~h}$. However, we are only using MODIS Aqua data in our comparisons, because the overpass time is closest to VIIRS (both sensors cross the equator at approximately 1330 local time), thereby minimizing any temporal biases in the PAR comparisons. MODIS has a swath width of $2330 \mathrm{~km}$ and views the entire Earth's surface every 1-2 days. The VIIRS swath width is $3000 \mathrm{~km}$ and orbits at a higher altitude than MODIS ( $824 \mathrm{~km}$ versus $705 \mathrm{~km}$ ), enabling observation of the entire Earth's surface twice each day.

For the time series and spatial analyses, level $1 \mathrm{~b}$ MODIS and VIIRS satellite imagery covering the Gulf of Mexico were downloaded from NASA and NOAA, respectively (https://ladsweb.modaps.eosdis.nasa.gov/, https://www.class.noaa.gov/). The files were subsequently processed through the Automated Processing System (APS) developed at the Naval Research Laboratory (NRL) at the Stennis Space Center (SSC) in Mississippi (see description in Gould et al. 2014; Automated Processing System User's Guide, Version 6.6.5; https://www7330.nrlssc.navy.mil/7331/docs/aps_v6.6/html/ user/aps.xhtml). APS incorporates the latest NASA MODIS/VIIRS code, with updates as they become available, and enables us to rapidly produce the standard NASA ocean color products (chlorophyll, PAR, etc.), as well as Navy-specific products (absorption/ backscattering coefficients, diver visibility, lidar penetration depth) using NRL algorithms. It takes about 8-10 min to process a single MODIS or VIIRS image granule on our system, from calibrated radiances to atmospherically corrected, mapped, bio-optical products. Furthermore, we can automatically extract image data from regions of interest to facilitate time series analyses and from specific locations for matchups with in situ ship or mooring data. All imagery was processed with atmospheric correction and bio-optical algorithms consistent with NASA SeaDAS version 7.1 and with time-dependent calibration coefficients (SeaDAS version 7.5 has recently been released by NASA and we are in the process of incorporating those version changes, but they do not affect the PAR algorithm).

PAR has been defined to cover the 350-700-nm spectral range, but it is typically reduced to $400-700 \mathrm{~nm}$, for practical considerations related to satellite wavelength band restrictions (Baker and Frouin 1987; Frouin and Murakami 2007). The Sea-Viewing Wide Field-of-View Sensor (SeaWiFS) algorithm, which is also applied to other ocean color sensors such as MODIS and VIIRS, provides an estimate of the daily (24-h average) PAR incident on the ocean surface, expressed in einsteins per square meter per day $\left(\mathrm{E} \mathrm{m}^{-2} \mathrm{day}^{-1}\right.$; Frouin et al. 2003). These daily averages are then converted to watts per square meter following Morel and Smith (1974):

$$
\begin{aligned}
& \operatorname{PAR}\left(\mathrm{W} \mathrm{m}^{-2}\right)= \\
& \frac{\operatorname{PAR}\left(\mathrm{E} \mathrm{m}^{-2} \mathrm{day}^{-1}\right) 6.023 \times 10^{23}\left(\text { quanta }^{-1}\right)}{86400\left(\mathrm{~s} \mathrm{day}^{-1}\right) 2.77 \times 10^{18}\left(\text { quanta s}^{-1} \mathrm{~W}^{-1}\right)}
\end{aligned}
$$

The SeaWiFS algorithm uses the top-of-the-atmosphere radiances measured in each of the bands in the 400 $700-\mathrm{nm}$ range that do not saturate over clouds (six bands for SeaWiFS, three for MODIS, and five for VIIRS). Thus, PAR values will be estimated for both clear and cloudy pixels. 


\section{c. Atmospheric models}

Gridded solar radiation fields used to force ocean hydrodynamic models are typically provided by numerical weather prediction products (Wallcraft et al. 2008). For example, for NCOM, the solar radiation can come from NOGAPS, COAMPS, or NAVGEM. These atmospheric models calculate $Q_{\mathrm{Sw}}$ through radiative transfer calculations, and the estimates are then used as input to the hydrodynamic model heat budget calculations (Hodur 1997; Hogan and Rosmond 1991; Hogan et al. 2014; Ko et al. 2016; Rosmond 1992; Rosmond et al. 2002; Shulman et al. 2017, 2013). Using 3-hourly analysis fields from each of the three atmospheric models, we calculated daily average shortwave radiation values and then converted those values to PAR using the same method as for the in situ daily averages [Eq. (1)].

NOGAPS is a global model gridded at $0.5^{\circ}$ spatial resolution that ended operational use in October 2013 and was replaced with NAVGEM. It uses the Harshvardhan et al. (1987) parameterization for longwave radiation and the Davies (1982) parameterization for shortwave radiation (Hogan and Rosmond 1991; Rosmond 1992). COAMPS Central America model is a regional, $0.2^{\circ}$ resolution model that uses the $\mathrm{Fu}-\mathrm{Liou}$ radiation parameterization (J. Doyle 2016, personal communication; http://www-cave.larc.nasa.gov/pages/ flp200503_web.htm); it ended operational use in May 2014 and was replaced with the COAMPS Equatorial Americas model at $0.15^{\circ}$ resolution. The model resolution, grid, and parameterization changed with the new version, and at the time of our analyses those model results were not available to us. NAVGEM is a global $0.5^{\circ}$ resolution model that started operational use in February 2013 (Hogan et al. 2014). It uses the RRTMG radiation parameterization (Clough et al. 2005; http:// rtweb.aer.com/). The atmospheric models do not assimilate MODIS or VIIRS radiances in their calculation of shortwave radiation; thus, the satellite and model PAR and $Q_{\text {sw }}$ estimates are independent.

\section{Results}

\section{a. PAR comparisons: Temporal}

We performed multiyear temporal comparisons between coincident model, satellite, and in situ datasets at the three station locations shown in Fig. 1. In situ data were available for different time periods at each location (see section 2). For the temporal comparisons, model values were extracted at the three in situ locations for the time periods corresponding to the in situ data. Only MODIS satellite data were used in the temporal comparisons because VIIRS was not operational during the time periods of the in situ data collections. Single satellite pixels and model grid points closest to the in situ data locations were selected for all comparisons. These analyses include both cloudy and clear-sky conditions from the satellites, although matchups with percent differences between the in situ and satellite values that exceeded $50 \%$ were excluded from the analyses. This is because the satellite daily-average PAR values are based on the pixel conditions at the time of the satellite overpass, whereas the in situ measurements were collected hourly and averaged over the entire day. Thus, any diurnal cloud variability would be captured by the in situ measurements, but not by the satellite estimate, and the results would be biased. Relative percent difference (RPD) was calculated for each day as

$$
\operatorname{RPD}(\%)=\frac{\left(\mathrm{PAR}_{\text {truth }}-\mathrm{PAR}_{\text {sat,model }}\right) \times 100}{\mathrm{PAR}_{\text {truth }}} .
$$

Average RPD (ARPD) was calculated as

$$
\operatorname{ARPD}(\%)=\frac{\sum_{i=1}^{n} \mathrm{RPD}_{i}}{n} .
$$

In Eq. (3), the subscript "sat, model" indicates that either a satellite or model dataset is the comparison dataset with the "truth" dataset. When available, the in situ data are always used as "truth." For the satellitemodel comparisons, the satellite data are used as truth. For the model-model comparisons, the model selected as "truth" for the comparison is arbitrary (but consistent); it is indicated in the legend for Table 2. For the scatterplots in Figs. 2-4, the dataset selected as "truth" is always on the $x$ axis.

Figures 2-4 illustrate a variety of model, satellite, and data comparisons for Terrebonne Bay, Southwest Pass, and oil platform ST-52, respectively. The red lines in the left-hand panels of each figure represent a Type II least squares regression best fit to the data. The red lines in the right-hand panels of each figure represent a Savitzky-Golay 60-point smoothing of the data. The comparison values discussed below are shown in Table 2, which summarizes the temporally averaged results. Significant daily variability is observed in all the comparisons, as indicated by the wide spread of points on the scatterplots and the large, high-frequency "spikes" on the time series plots.

\section{1) Terrebonne BAy}

Although MODIS and in situ measurements agree quite closely when averaged over time (Fig. 2a; 
TABLE 2. Temporal PAR comparisons between satellite (MODIS), model (COAMPS, NOGAPS), and in situ measurements from three ground locations (Terrebonne Bay, Southwest Pass, and Chevron oil platform ST-52). Corresponding figures are indicated. Time periods covered at each location are indicated in parentheses. For the two comparison datasets, the second dataset listed is the "truth" dataset in Eq. (3).

\begin{tabular}{|c|c|c|c|c|c|c|}
\hline Comparison & Figures & $N$ & $R^{2}$ & $\operatorname{Bias}\left(\mathrm{W} \mathrm{m}^{-2}\right)$ & $\operatorname{RMSE}\left(\mathrm{W} \mathrm{m}^{-2}\right)$ & $\operatorname{ARPD}(\%)$ \\
\hline \multicolumn{7}{|c|}{ Terrebonne Bay (January 2010-December 2011) } \\
\hline MODIS, in situ & Figs. 2a,b & 562 & 0.985 & 1.763 & 13.449 & -1.48 \\
\hline COAMPS, in situ & Figs. 2c,d & 655 & 0.967 & -10.584 & 19.853 & 9.02 \\
\hline NOGAPS, in situ & Figs. 2e,f & 624 & 0.966 & -6.705 & 17.002 & 4.68 \\
\hline COAMPS, MODIS & Figs. $2 \mathrm{~g}, \mathrm{~h}$ & 563 & 0.970 & -12.928 & 21.945 & 10.56 \\
\hline NOGAPS, MODIS & Figs. 2i,j & 561 & 0.968 & -10.414 & 20.243 & 7.61 \\
\hline NOGAPS, COAMPS & Figs. $2 \mathrm{k}, 1$ & 639 & 0.974 & 3.183 & 14.592 & -5.77 \\
\hline \multicolumn{7}{|c|}{ Southwest Pass (January-November 2006 and January-September 2007) } \\
\hline MODIS, in situ & Figs. 3a,b & 250 & 0.972 & 7.563 & 18.636 & -6.13 \\
\hline COAMPS, in situ & Figs. 3c,d & 469 & 0.966 & -1.624 & 17.644 & 1.57 \\
\hline NOGAPS, in situ & Figs. 3e,f & 446 & 0.965 & 1.045 & 18.620 & -1.18 \\
\hline COAMPS, MODIS & Figs. 3g,h & 285 & 0.968 & -11.868 & 22.228 & 8.72 \\
\hline NOGAPS, MODIS & Figs. $3 i, j$ & 280 & 0.973 & -9.312 & 20.174 & 6.76 \\
\hline NOGAPS, COAMPS & Figs. $3 \mathrm{k}, 1$ & 549 & 0.969 & 0.979 & 17.992 & -2.61 \\
\hline \multicolumn{7}{|c|}{ Chevron oil platform ST-52 (October 2010-March 2012) } \\
\hline MODIS, in situ & Figs. $4 \mathrm{a}, \mathrm{b}$ & 425 & 0.987 & 5.941 & 12.287 & -6.76 \\
\hline COAMPS, in situ & Figs. $4 \mathrm{c}, \mathrm{d}$ & 455 & 0.961 & -6.680 & 16.602 & 6.27 \\
\hline NOGAPS, in situ & Figs. $4 \mathrm{e}, \mathrm{f}$ & 436 & 0.969 & 1.730 & 12.440 & -3.06 \\
\hline COAMPS, MODIS & Figs. $4 \mathrm{~g}, \mathrm{~h}$ & 443 & 0.966 & -11.923 & 20.445 & 10.93 \\
\hline NOGAPS, MODIS & Figs. 4i,j & 445 & 0.967 & -4.960 & 15.300 & 3.70 \\
\hline NOGAPS, COAMPS & Figs. 4k,1 & 462 & 0.970 & 5.716 & 14.728 & -8.32 \\
\hline
\end{tabular}

ARPD $=-1.48 \%$ ), a seasonal trend is also observed in the comparison, with MODIS values exceeding the ground truth measurements in the summer (Fig. 2b). This trend is masked if just the ARPD is examined. COAMPS values are generally less than the in situ values, with a bias of $-10.58 \mathrm{~W} \mathrm{~m}^{-2}$ and a consistently positive ARPD of $9.02 \%$ (Figs. 2c,d). NOGAPS comparisons to in situ data show similar trends (Figs. 2e,f). COAMPS (Figs. 2g,h) and NOGAPS (Figs. 2i,j) values are also less than MODIS, and the biases and RMSEs $\left(21.94\right.$ and $20.24 \mathrm{~W} \mathrm{~m}^{-2}$, respectively) are higher, as are the ARPD values (10.56 and $7.61 \%$, respectively). The two models (NOGAPS, COAMPS) agree quite closely with each other (Figs. 2k, 1), with NOGAPS values slightly exceeding COAMPS, on average $(\mathrm{ARPD}=-5.77 \%)$.

\section{2) Southwest Pass}

The seasonal trend between the MODIS and in situ data that was observed at Terrebonne Bay is also observed here, although the ARPD is greater (Figs. 3a,b; ARPD $=-6.13 \%)$. At this location COAMPS and in situ data agree quite closely on average (Fig. 3C, D), with bias, RMSE, and ARPD values of $-1.62 \mathrm{~W} \mathrm{~m}^{-2}$, $17.64 \mathrm{~W} \mathrm{~m}^{-2}$, and $1.57 \%$, respectively. The NOGAPS comparison to the in situ data is quite similar (Figs. 3e,f). Some seasonal variability is also observed in the
COAMPS and NOGAPS comparisons with the in situ data (Figs. 3d,f). Both COAMPS and NOGAPS are again lower than MODIS, with bias, RMSE, and ARPD values $(8.72 \%$ and $6.76 \%$, respectively) similar to those at Terrebonne Bay (Figs. 3g,h and 3i,j, respectively). As at Terrebonne Bay, the average NOGAPS and COAMPS values are quite similar (Figs. $3 \mathrm{k}, 1$ ), with an ARPD $=-2.61 \%$.

\section{3) Chevron Platform ST-52}

The seasonal trend that was observed between the MODIS and in situ values at Terrebonne Bay and Southwest Pass is not apparent at this location. Here, MODIS values show a positive bias, with an ARPD $=-6.76 \%$ (Figs. 4a,b). As at Terrebonne Bay, COAMPS values are generally less than in situ values, with a bias of $-6.68 \mathrm{~W} \mathrm{~m}^{-2}$ and a consistently positive ARPD of $6.27 \%$ (Figs. 4c,d). As at Southwest Pass, the NOGAPS values are quite similar to the in situ, however, with a bias of $1.73 \mathrm{~W} \mathrm{~m}^{-2}$ and ARPD $=-3.06 \%$ (Figs. $4 \mathrm{e}, \mathrm{f}$ ). As at the other two locations, both COAMPS and NOGAPS are again lower than MODIS, with ARPD values of $10.93 \%$ and $3.70 \%$ (Figs. 4g,h and $4 \mathrm{i}, \mathrm{j}$, respectively). NOGAPS and COAMPS do not agree as closely as at the other two locations. Here, NOGAPS generally exceeds COAMPS (bias $=5.71 \mathrm{~W} \mathrm{~m}^{-2}$, ARPD $=-8.32 \%$ ). 

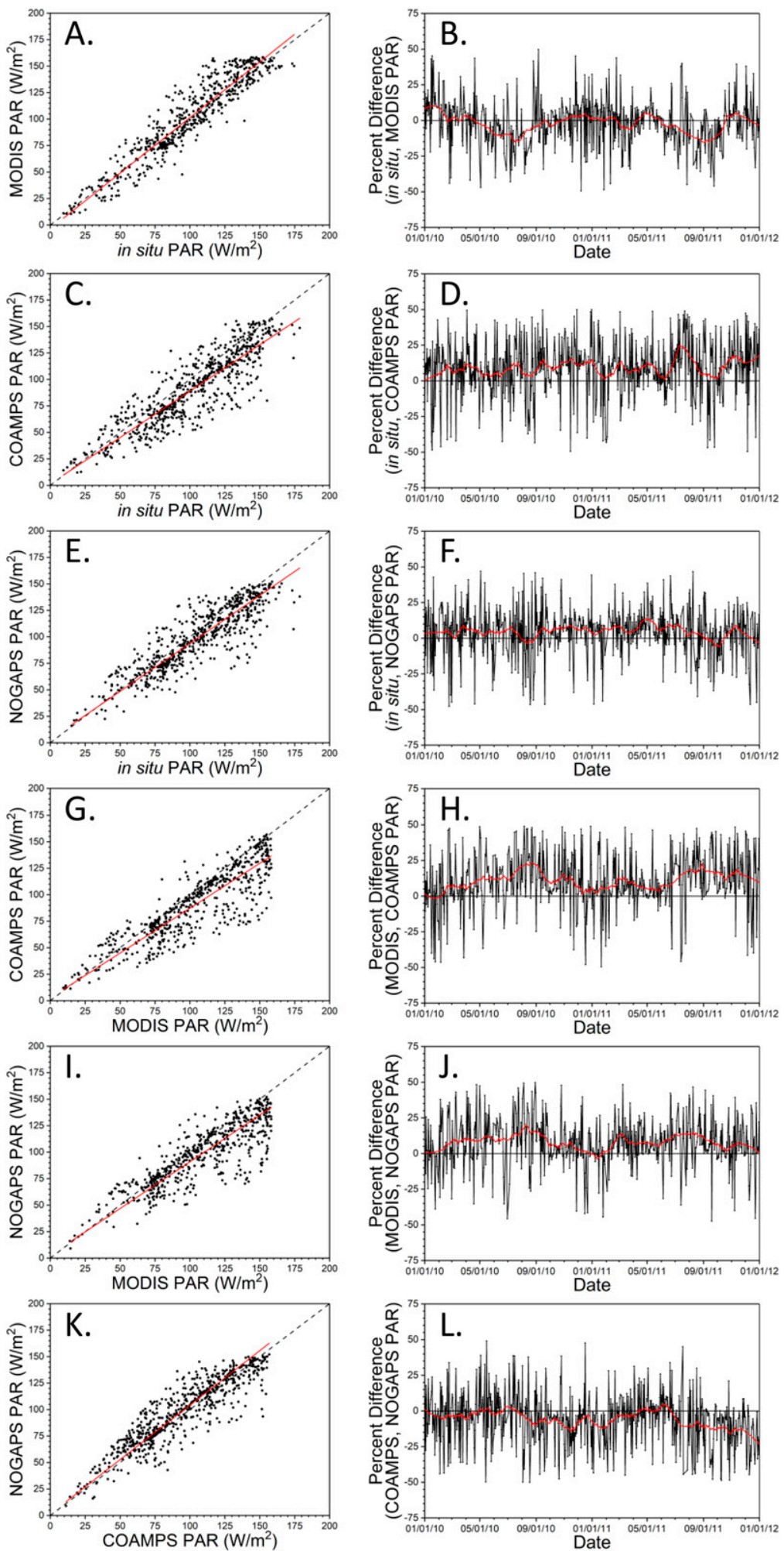

FIG. 2. Temporal PAR comparisons, Terrebonne Bay. (a) MODIS vs in situ. (b) RPD between MODIS and in situ vs date. (c) COAMPS vs in situ. (d) RPD between COAMPS and in situ vs date. (e) NOGAPS vs in situ. (f) RPD between NOGAPS and in situ vs date. (g) COAMPS vs MODIS. (h) RPD between COAMPS and MODIS vs date. (i) NOGAPS vs MODIS. (j) RPD between NOGAPS and MODIS vs date. (k) NOGAPS vs COAMPS. (l) RPD between NOGAPS and COAMPS vs date. 

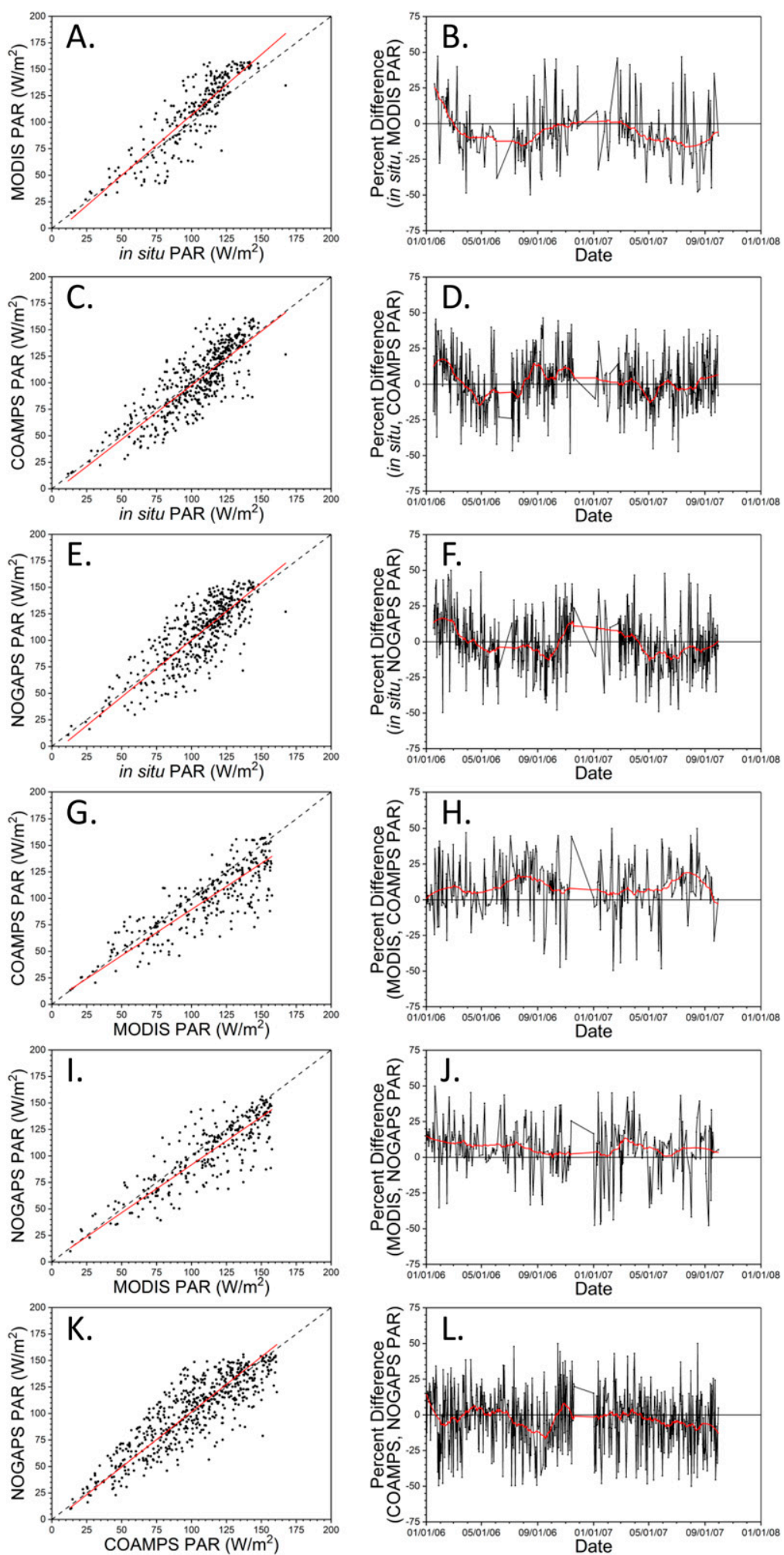

FIG. 3. Temporal PAR comparisons, Southwest Pass. (a) MODIS vs in situ. (b) RPD between MODIS and in situ vs date. (c) COAMPS vs in situ. (d) RPD between COAMPS and in situ vs date. (e) NOGAPS vs in situ. (f) RPD between NOGAPS and in situ vs date. (g) COAMPS vs MODIS. (h) RPD between COAMPS and MODIS vs date. (i) NOGAPS vs MODIS. (j) RPD between NOGAPS and MODIS vs date. (k) NOGAPS vs COAMPS. (l) RPD between NOGAPS and COAMPS vs date. 

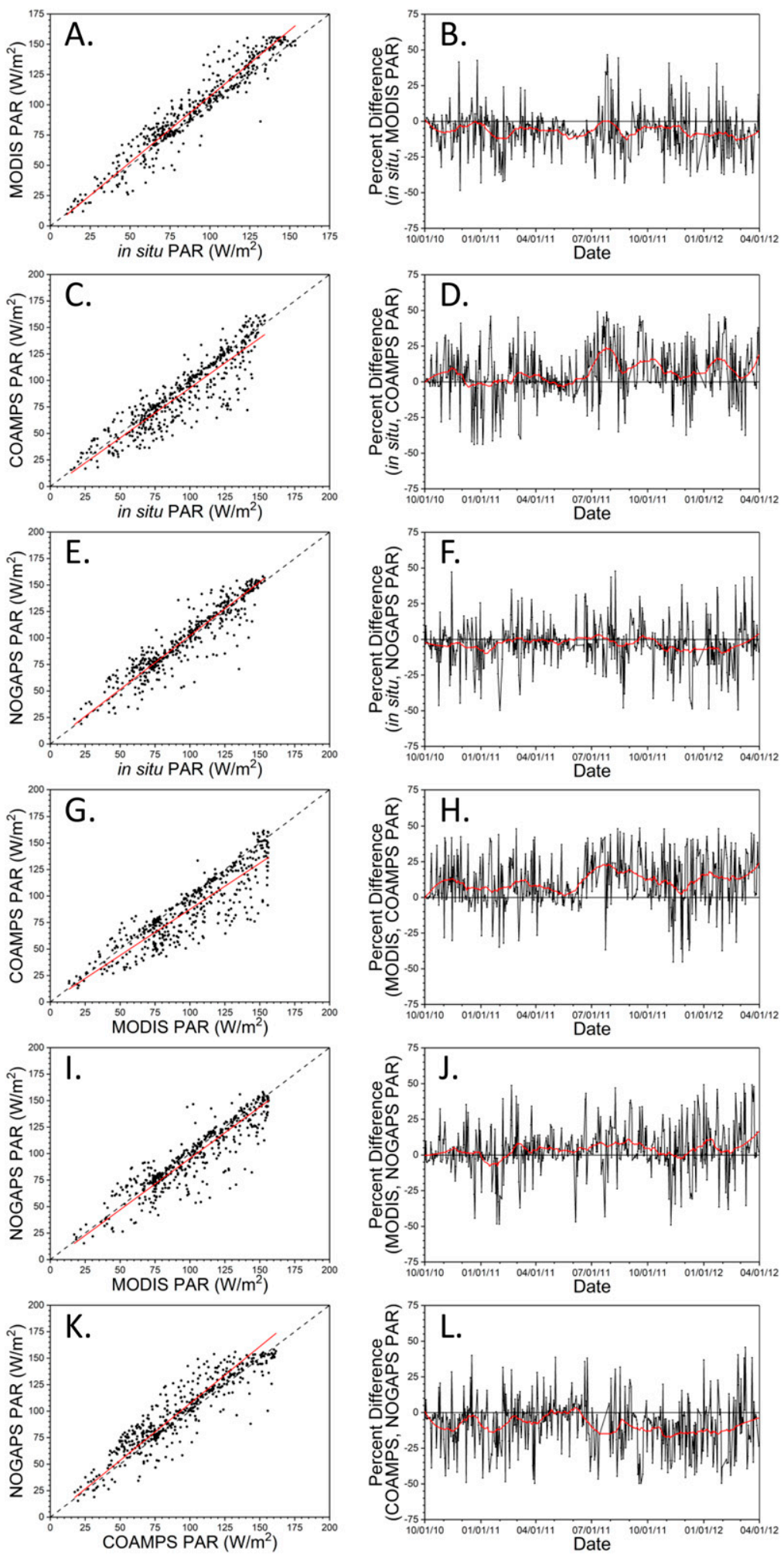

FIG. 4. Temporal PAR comparisons, Chevron oil platform ST-52. (a) MODIS vs in situ. (b) RPD between MODIS and in situ vs date. (c) COAMPS vs in situ. (d) RPD between COAMPS and in situ vs date. (e) NOGAPS vs in situ. (f) RPD between NOGAPS and in situ vs date. (g) COAMPS vs MODIS. (h) RPD between COAMPS and MODIS vs date. (i) NOGAPS vs MODIS. (j) RPD between NOGAPS and MODIS vs date. (k) NOGAPS vs COAMPS. (l) RPD between NOGAPS and COAMPS vs date. 
To summarize the results of the temporal PAR comparisons, which include both cloudy and clear-sky conditions:

\section{MODIS PAR $>$ in situ PAR $\geq$ NOGAPS PAR $>$ COAMPS PAR.}

The summary ARPD values averaged over all three locations are listed in Table 3.

\section{b. PAR comparisons: Spatial}

We performed spatial comparisons across the green region of interest in Fig. 1. Model-derived PAR values were remapped to the 1-km satellite grid, extracted over the region of interest, and compared to satellite values at each pixel location, for each of the nine individual satellite scenes listed in Table 1. Cloud pixels were masked for these analyses to prevent different cloud patterns between MODIS and VIIRS scenes (due to time differences) and spatial resolution differences between the imagery $(1 \mathrm{~km})$ and the models $\left(0.2^{\circ}-0.5^{\circ}\right)$ from biasing results. Because of the time differences between the MODIS and VIIRS overpasses on the same day, different pixels will be cloud covered in the two images due to the cloud movement. If we do not mask the cloud pixels, we would be introducing a bias in the results, by comparing clouded pixels in one image with cloud-free pixels in the other image. Thus, these analyses represent only clear-sky conditions.

Satellite scenes selected for the spatial analyses were chosen based on clear coverage (i.e., fewest clouded pixels over the entire extent of the green region of interest in Fig. 1), to facilitate the cloud-screening process and ensure a maximal number of matchups. To mask clouds, we first combined the satellite and model data for an individual day into a single, remapped file at $1-\mathrm{km}$ spatial resolution (the highest spatial resolution of the datasets, which corresponded to the satellite resolution). Cloud masking was performed on each of these daily combined files separately using a bandthreshold approach on the satellite PAR data. Through visual examination (e.g., PAR below a certain value), we determined whether a pixel was clouded in either the MODIS or VIIRS image. If cloudy, it was masked and not included in the analyses (thus, the associated remapped model grid cells were also excluded). The model data files were not cloud-screened separately, but visual inspection determined that our satellite cloud-screening process on the combined file also removed nearly all of the model cloud-contaminated grid cells as well, so the impact of any remaining cloud-contaminated satellite pixels and/or model grid cells will be minimal.
TABLE 3. Temporal PAR comparisons between satellite (MODIS), model (COAMPS, NOGAPS), and in situ measurements from three ground locations (Terrebonne Bay, Southwest Pass, and Chevron oil platform ST-52). Summary of results averaged over all three locations (cloudy and clear-sky conditions).

\begin{tabular}{lc}
\hline \hline \multicolumn{1}{c}{ Comparison result } & ARPD $(\%)$ \\
\hline MODIS > in situ & 4.79 \\
In situ > COAMPS & 5.62 \\
In situ > NOGAPS & 0.15 \\
MODIS > COAMPS & 10.07 \\
MODIS > NOGAPS & 6.02 \\
NOGAPS > COAMPS & 5.57 \\
\hline
\end{tabular}

Cloud masking was not performed for the time series analyses because only a single satellite sensor was used in the comparisons with the in situ and model datasets (MODIS, VIIRS data were not available), so the time differential problem does not exist. Thus, the time series analysis, which includes both cloudy and cloudfree conditions, allows for performance assessment for cloudy conditions. Figure 5 shows the PAR values derived from MODIS, COAMPS, and NOGAPs for 21 October 2011, to illustrate the three products at their native spatial resolutions (VIIRS resolution is the same as MODIS, $1 \mathrm{~km}$, and NAVGEM resolution is the same as NOGAPS, $0.5^{\circ}$ ). However, as mentioned, the model results were remapped to the satellite grid for the spatial analyses.

In the RPD calculation for the spatial comparisons, the satellite (MODIS or VIIRS) data are used as the "truth," instead of the in situ data as for the temporal comparisons [Eq. (3)], because in situ data are only available at three specific locations, not spatially across the image and model domains. For the MODIS-VIIRS comparisons, MODIS was selected as "truth," although that designation is arbitrary (it just needs to be consistent). For the model-model comparisons, the model selected as "truth" for each comparison is also arbitrary but consistent; it is indicated in the legend for Table 4. For Figs. 6-10, the dataset selected as "truth" is always on the $x$ axis.

The comparison values discussed below are shown in Table 4, which summarizes the spatially averaged results. Comparisons of coincident satellite (MODIS, VIIRS) and model (NOGAPS, COAMPS, NAVGEM) datasets listed in Table 1 are shown in Figs. 6-8. Note the axis ranges change due to seasonal PAR variability. The comparisons of both COAMPS and NOGAPS to MODIS show fairly good agreement (Figs. 6, 7), with ARPD values ranging from $-4.77 \%$ to $2.16 \%$. Both NOGAPS and COAMPS PAR values are generally slightly higher than MODIS (i.e., negative ARPD values), except COAMPS on 21 October 2011 and 

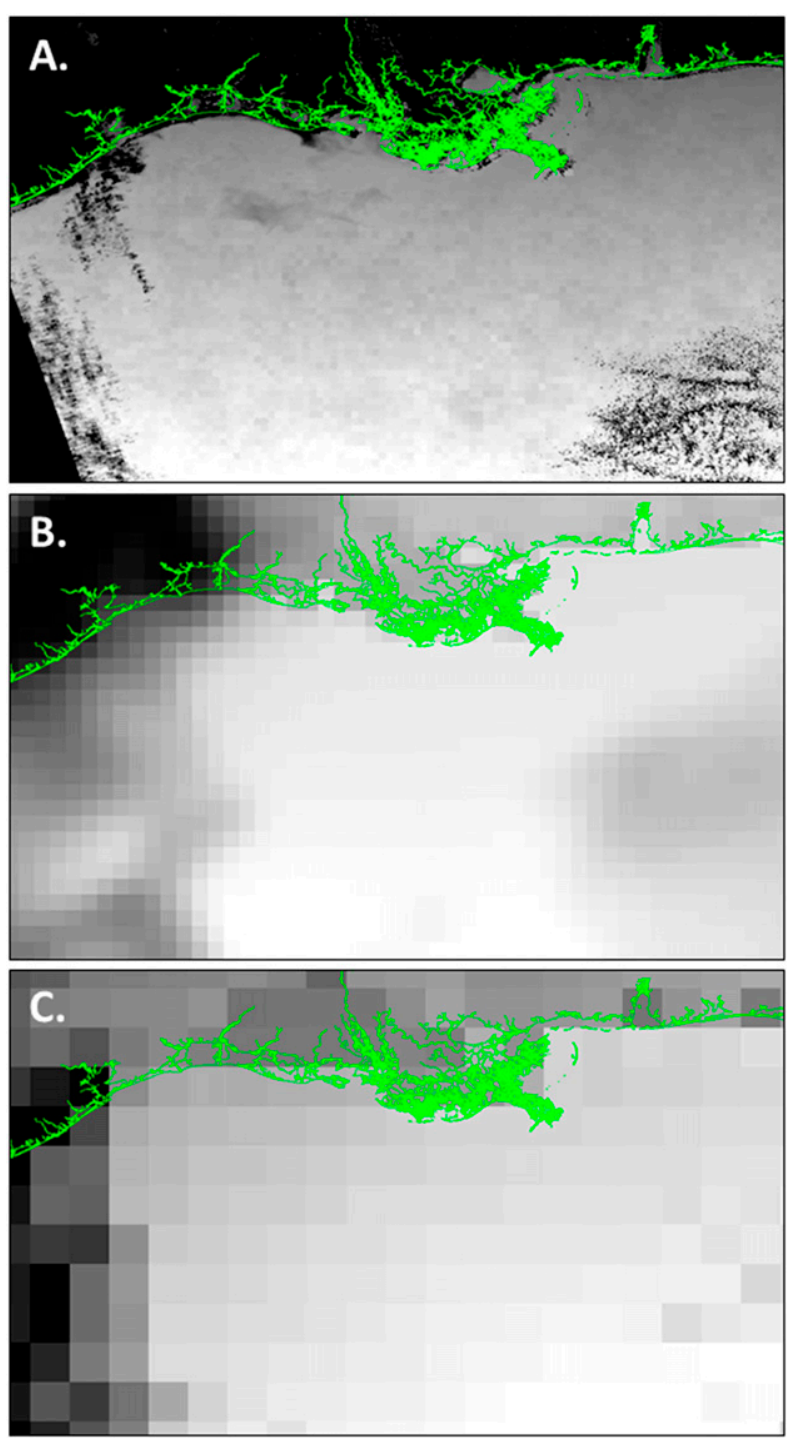

FIG. 5. PAR comparison, 21 Oct 2011. (a) MODIS, 1-km resolution. (b) COAMPS, $0.2^{\circ}$ resolution. (c) NOGAPS, $0.5^{\circ}$ resolution (NAVGEM is also $0.5^{\circ}$ resolution, but model results are not available for this date). For spatial comparisons, model data were resampled to $1-\mathrm{km}$ satellite resolution.

22 January 2014 (Figs. 7a,e). For 22 January 2014, the distribution of COAMPS data is split between positive and negative biases, resulting in a low, positive ARPD $(0.42 \%$; Fig. 7 e) . Both COAMPS and NOGAPS are also higher than VIIRS, for all comparisons (Figs. 6, 7), and to a greater extent than they are for MODIS (ARPD values from $-8.61 \%$ to $-4.68 \%$ ). In contrast, MODIS values are higher than NAVGEM values in all five comparisons, while VIIRS values are close to NAVGEM (Fig. 8). ARPD values between NAVGEM and MODIS ranged from $2.72 \%$ to $7.61 \%$, and ARPD values between NAVGEM and VIIRS ranged from $-2.10 \%$ to $3.04 \%$.
The MODIS and VIIRS scenes on 22 April 2012 and 4 May 2013 show smaller ranges of PAR variability compared to the other dates (Figs. 6-8, 10). This is possibly due to the smaller range of PAR variability across this latitudinal band $\left(25^{\circ}-30^{\circ} \mathrm{N}\right)$ during this time period (late spring) relative to the other image dates (fall and winter). See Fig. 1 in Campbell and Aarup (1989), which shows latitudinal/seasonal variability in PAR. The lower PAR ranges for these dates are also evident to some degree in the NOGAPS and COAMPS model data (Figs. 6, 7). The horizontal "striations" in Figs. 6-8 data give an indication of the model subgrid variability (i.e., there are multiple MODIS and VIIRS pixels at 1-km resolution contained in a single COAMPS grid cell at $0.2^{\circ}$ resolution or a NOGAPS or NAVGEM grid cell at $0.5^{\circ}$ resolution). However, additional statistical analysis of these datasets to more stringently estimate subgrid variability (such as calculating the standard deviation of all MODIS pixels contained in each of the individual COAMPS, NOGAPS, and NAVGEM grid cells) is beyond the scope of this work.

For the model/model comparisons (Fig. 9), COAMPS and NOGAPS agree quite well with low biases, except for 21 October 2011 (Fig. 9a), which has a somewhat larger bias of $-4.90 \mathrm{~W} \mathrm{~m}^{-2}$. Both positive (COAMPS $>$ NOGAPS) and negative biases are observed (Table 4; Figs. 9a-d). There is only one COAMPS and NAVGEM comparison (22 January 2014); in Fig. 9e, COAMPS values generally exceed the NAVGEM values (bias $=2.10 \mathrm{~W} \mathrm{~m}^{-2}, \mathrm{ARPD}=-2.58 \%$ ).

For the satellite/satellite comparisons, MODIS values exceed the VIIRS values for all comparisons (Fig. 10), with ARPD values ranging from 3.20 to 5.36\% (Table 4) and an average value of $4.33 \%$ (Table 5). VIIRS and MODIS Aqua have similar afternoon overpass times with a local equatorial crossing time of about 1330 . The time differentials between the MODIS and VIIRS overpasses in our comparisons range from about 5 to $65 \mathrm{~min}$ (MODIS pass is generally later than VIIRS, but not always). Because the PAR algorithm integrates over the length of the day, the time of overpass should not matter (i.e., should not contribute to the observed biases). Thus, the persistent observed trend with MODIS PAR $>$ VIIRS PAR is unrelated to differences in overpass times between the two sensors. The $4.33 \%$ ARPD between MODIS and VIIRS is slightly larger than the $2 \%-3 \%$ intersensor biases between SeaWiFS, MODIS Aqua, and MODIS Terra reported for clear-sky conditions in Frouin et al. (2012). They attributed the differences to the accuracy of the clear-sky model and the calculation of the spectrally integrated transmittance functions. In addition, sensor calibration differences 
TABLE 4. Spatial PAR comparisons between satellite (MODIS, VIIRS) and model (COAMPS, NOGAPS, NAVGEM) values for nine dates. Corresponding figures are indicated. For the two comparison datasets, the second dataset listed is the "truth" dataset in Eq. (3).

\begin{tabular}{|c|c|c|c|c|c|}
\hline Comparison & Figures & $N$ & $\operatorname{Bias}\left(\mathrm{W} \mathrm{m}^{-2}\right)$ & $\operatorname{RMSE}\left(\mathrm{W} \mathrm{m}^{-2}\right)$ & ARPD (\%) \\
\hline \multicolumn{6}{|c|}{21 Oct 2011} \\
\hline COAMPS, MODIS & Fig. 7a & 167553 & -2.27 & 2.89 & 2.16 \\
\hline NOGAPS, MODIS & Fig. 6a & 167553 & 2.62 & 3.05 & -2.50 \\
\hline COAMPS, NOGAPS & Fig. 9a & 167553 & -4.90 & 5.18 & 4.54 \\
\hline \multicolumn{6}{|c|}{22 Apr 2012} \\
\hline COAMPS, MODIS & Fig. 7b & 167553 & 2.11 & 2.27 & -1.44 \\
\hline COAMPS, VIIRS & Fig. 7b & 167553 & 7.21 & 7.28 & -5.12 \\
\hline NOGAPS, MODIS & Fig. $6 b$ & 167553 & 1.48 & 3.19 & -1.02 \\
\hline NOGAPS, VIIRS & Fig. $6 \mathrm{~b}$ & 167553 & 6.58 & 7.20 & -4.68 \\
\hline COAMPS, NOGAPS & Fig. $9 b$ & 167553 & 0.62 & 2.69 & -0.46 \\
\hline VIIRS, MODIS & Fig. 10a & 167553 & -5.10 & 5.15 & 3.49 \\
\hline \multicolumn{6}{|c|}{18 Dec 2012} \\
\hline COAMPS, MODIS & Fig. $7 \mathrm{c}$ & 167186 & 0.55 & 0.83 & -0.73 \\
\hline COAMPS, VIIRS & Fig. $7 \mathrm{c}$ & 165077 & 4.68 & 4.74 & -6.46 \\
\hline NOGAPS, MODIS & Fig. 6c & 167186 & 1.31 & 1.43 & -1.71 \\
\hline NOGAPS, VIIRS & Fig. $6 \mathrm{c}$ & 165077 & 5.44 & 5.48 & -7.50 \\
\hline COAMPS, NOGAPS & Fig. 9c & 167186 & -0.76 & 0.92 & 0.96 \\
\hline VIIRS, MODIS & Fig. 10b & 164837 & -4.11 & 4.14 & 5.36 \\
\hline \multicolumn{6}{|c|}{4 May 2013} \\
\hline COAMPS, MODIS & Fig. $7 d$ & 167402 & 7.12 & 7.21 & -4.77 \\
\hline COAMPS, VIIRS & Fig. $7 d$ & 49162 & 12.44 & 12.46 & -8.61 \\
\hline NOGAPS, MODIS & Fig. 6d & 167402 & 4.47 & 5.30 & -3.00 \\
\hline NOGAPS, VIIRS & Fig. 6d & 49162 & 9.40 & 10.59 & -6.51 \\
\hline COAMPS, NOGAPS & Fig. 9d & 167402 & 2.65 & 3.90 & -1.76 \\
\hline VIIRS, MODIS & Fig. 10c & 49162 & -4.77 & 4.83 & 3.20 \\
\hline \multicolumn{6}{|c|}{22 Jan 2014} \\
\hline COAMPS, MODIS & Fig. $7 \mathrm{e}$ & 167553 & -0.43 & 3.46 & 0.42 \\
\hline COAMPS, VIIRS & Fig. $7 \mathrm{e}$ & 167553 & 3.81 & 5.08 & -4.73 \\
\hline NAVGEM, MODIS & Fig. $8 \mathrm{a}$ & 167553 & -2.53 & 2.57 & 2.93 \\
\hline NAVGEM, VIIRS & Fig. 8 a & 167553 & 1.71 & 1.82 & -2.10 \\
\hline COAMPS, NAVGEM & Fig. $9 \mathrm{e}$ & 167553 & 2.10 & 3.86 & -2.58 \\
\hline VIIRS, MODIS & Fig. 10d & 167553 & -4.24 & 4.26 & 4.92 \\
\hline \multicolumn{6}{|c|}{25 Oct 2014} \\
\hline NAVGEM, MODIS & Fig. 8b & 166107 & -2.78 & 2.98 & 2.72 \\
\hline NAVGEM, VIIRS & Fig. $8 b$ & 165840 & 1.41 & 1.76 & -1.46 \\
\hline VIIRS, MODIS & Fig. 10e & 164765 & -4.19 & 4.20 & 4.12 \\
\hline \multicolumn{6}{|c|}{27 Jan 2015} \\
\hline NAVGEM, MODIS & Fig. $8 \mathrm{c}$ & 163987 & -6.76 & 6.93 & 7.61 \\
\hline NAVGEM, VIIRS & Fig. $8 c$ & 163235 & -2.56 & 3.00 & 3.04 \\
\hline VIIRS, MODIS & Fig. 10f & 161059 & -4.20 & 4.20 & 4.72 \\
\hline \multicolumn{6}{|c|}{10 Feb 2016} \\
\hline NAVGEM, MODIS & Fig. 8d & 163977 & -5.18 & 5.36 & 5.24 \\
\hline NAVGEM, VIIRS & Fig. 8d & 164612 & -0.72 & 1.54 & 0.74 \\
\hline VIIRS, MODIS & Fig. $10 \mathrm{~g}$ & 162144 & -4.47 & 4.47 & 4.54 \\
\hline \multicolumn{6}{|c|}{25 Feb 2016} \\
\hline NAVGEM, MODIS & Fig. $8 \mathrm{e}$ & 152540 & -5.51 & 5.59 & 5.00 \\
\hline NAVGEM, VIIRS & Fig. $8 \mathrm{e}$ & 167294 & -0.81 & 1.28 & 0.76 \\
\hline VIIRS, MODIS & Fig. 10h & 152339 & -4.69 & 4.69 & 4.26 \\
\hline
\end{tabular}

could contribute to the observed biases, as mentioned in Laliberté et al. (2016). The "box type" shapes toward the upper right of the scatterplot distributions in Figs. 10e-g are due to cloud-edge pixels that were not completely removed from the analyses due to inadequacies with the cloud screening process for those days.

As expected, spatial variability over the limited extent examined is much less than the multiyear temporal 

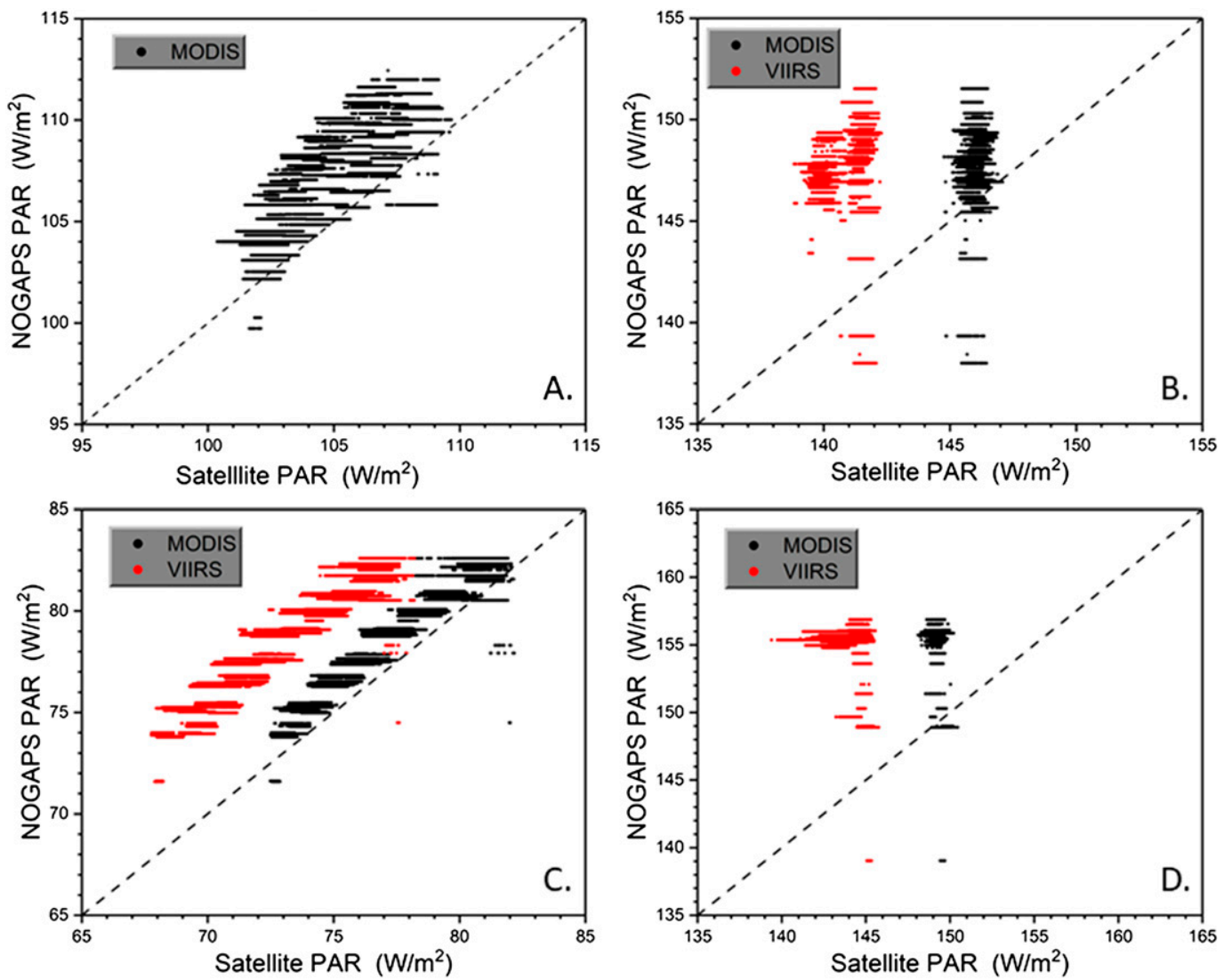

FIG. 6. Spatial PAR comparisons, NOGAPS vs MODIS and VIIRS. (a) 21 Oct 2011. (b) 22 Apr 2012. (c) 18 Dec 2012. (d) 4 May 2013.

variability. To summarize the results of the spatial PAR comparisons, which include only clear-sky conditions:

\section{NOGAPS PAR $\geq$ COAMPS PAR $\geq$ MODIS PAR$$
>\text { VIIRS PAR } \geq \text { NAVGEM PAR. }
$$

The summary ARPD values averaged over all dates are listed in Table 5.

\section{Discussion}

We compared model and satellite-derived PAR estimates to in situ measurements in the northern Gulf of Mexico, both spatially and temporally. For the temporal comparisons, we examined differences between in situ measurements (at specific locations) and satellite and model values (at $1-\mathrm{km}$ and $0.2-0.5^{\circ}$ resolutions, respectively). It is possible that the spatial resolution mismatch could impact results, as there will likely be somewhat greater variability in the larger model grid cell than in the smaller satellite pixel. However, due to the fairly large spatial scales over which PAR varies, and the similar satellite/in situ and model/in situ errors observed at all three stations (Figs. 2-4; Table 2), we do not believe resolution differences are significant (i.e., model errors are not significantly higher).

We observed a seasonal trend in the in situ/satellite differences at the two coastal stations, but not at the offshore station (oil platform). It is possible that proximity to land could be contributing to the seasonal pattern observed at the coastal stations. Recent work by Bulgarelli and colleagues indicates that the presence of nearby land can impact top-of-the-atmosphere radiance values of coastal water pixels (adjacency effects; Bulgarelli and Zibordi 2018a). Furthermore, these effects can lead to seasonal patterns in the ocean color remote sensing reflectance spectra (and therefore in derived properties, such as PAR, as well; Bulgarelli and Zibordi 2018b). Another (less likely) possibility is that there could be nearshore seasonal aerosol changes that are not adequately accounted for (removed) by the atmospheric correction routine applied to the satellite imagery. 

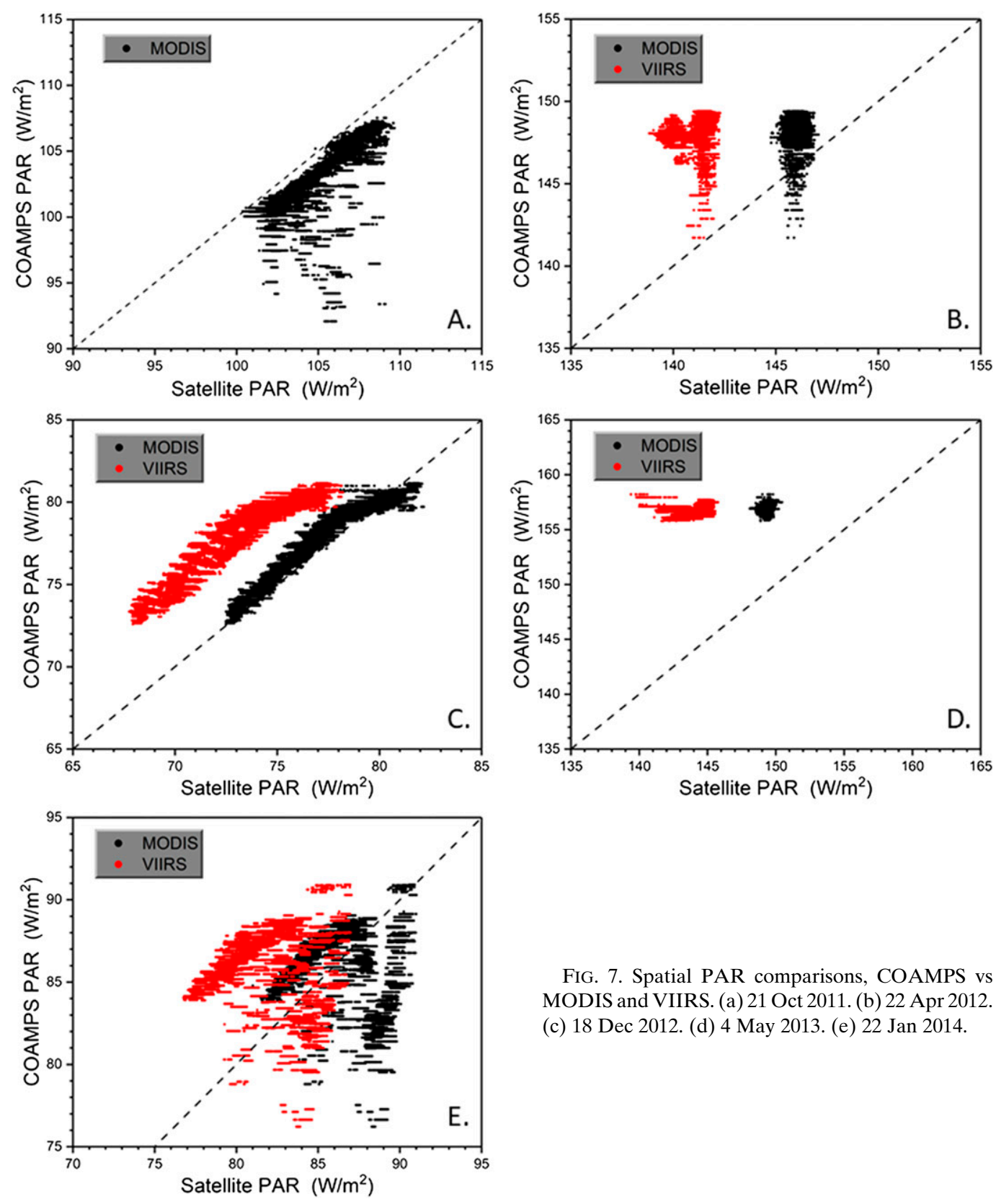

FIG. 7. Spatial PAR comparisons, COAMPS vs MODIS and VIIRS. (a) 21 Oct 2011. (b) 22 Apr 2012. (c) 18 Dec 2012. (d) 4 May 2013. (e) 22 Jan 2014.

The Frouin et al. (2003) algorithm we applied to estimate PAR from the ocean color satellite data assumes the effects of clouds and clear atmosphere can be decoupled, and this is modeled as a clear-sky atmosphere positioned above a cloud layer. With this approach, it is unnecessary to distinguish between clear and cloudy regions within a pixel, and there is no need for assumptions about cloud coverage distribution. The algorithm works on a pixel-by-pixel basis, for each pixel not contaminated by sun glint (glint areas would be interpreted as clouds by the algorithm).
Assumptions in the satellite PAR algorithm can cause some of the daily discrepancies with the model and in situ values. For example, the cloud-surface system is assumed stable during the day, and corresponds to the satellite observation. The daily average is derived from the radiance measurements at the time of the overpass. In other words, if a pixel is cloudy at the time of the overpass, it is assumed cloudy for the entire day; if clear during the overpass, clear all day. Thus, PAR accuracy is degraded where clouds exhibit strong diurnal variability. This is a weakness for daily 

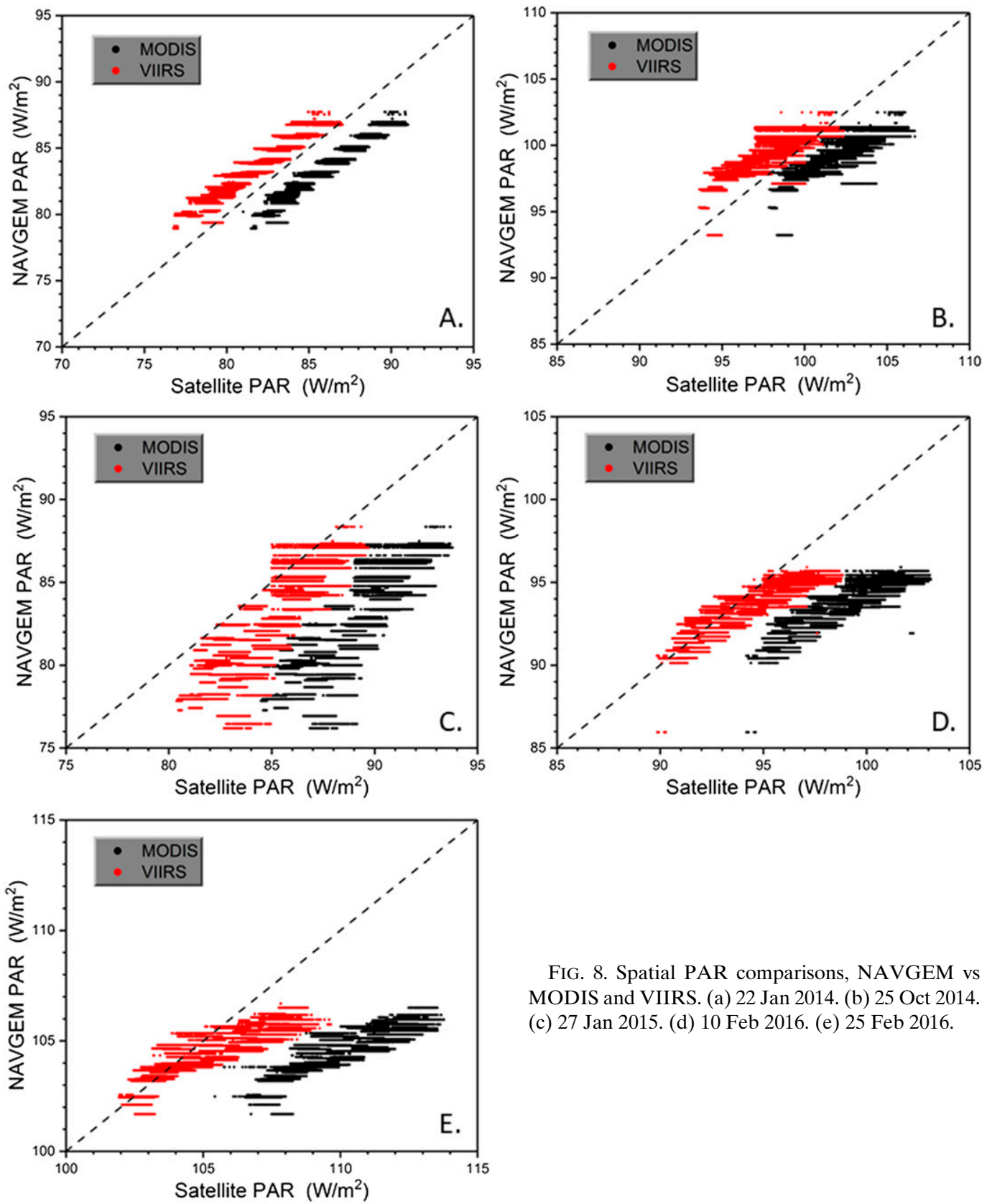

FIG. 8. Spatial PAR comparisons, NAVGEM vs MODIS and VIIRS. (a) 22 Jan 2014. (b) 25 Oct 2014. (c) 27 Jan 2015. (d) 10 Feb 2016. (e) 25 Feb 2016.

comparisons with model and in situ results, but spatial and temporal averaging can reduce the effect (Frouin et al. 2003).

For the temporal comparisons, we observed that COAMPS and NOGAPS PAR values $<$ MODIS values, whereas for the spatial comparisons, we observed the opposite. This could be related to the inclusion of both clear and cloudy conditions in the temporal comparisons and only clear conditions in the spatial comparisons. However, it could also relate to the limited temporal variability encompassed by the spatial comparisons. The spatial comparisons for MODIS/COAMPS/NOGAPS are only for four or five scenes (two in winter, two in spring, and one in fall; see Table 1) and thus represent only limited temporal variability (the variability observed in the spatial comparisons was much less than the variability observed in the multiyear temporal comparisons). So, it is also possible that if we were to examine a more complete, extensive time series of the spatial scenes, the pattern might switch to match that observed for the temporal comparison. It is difficult to say with any certainty why 

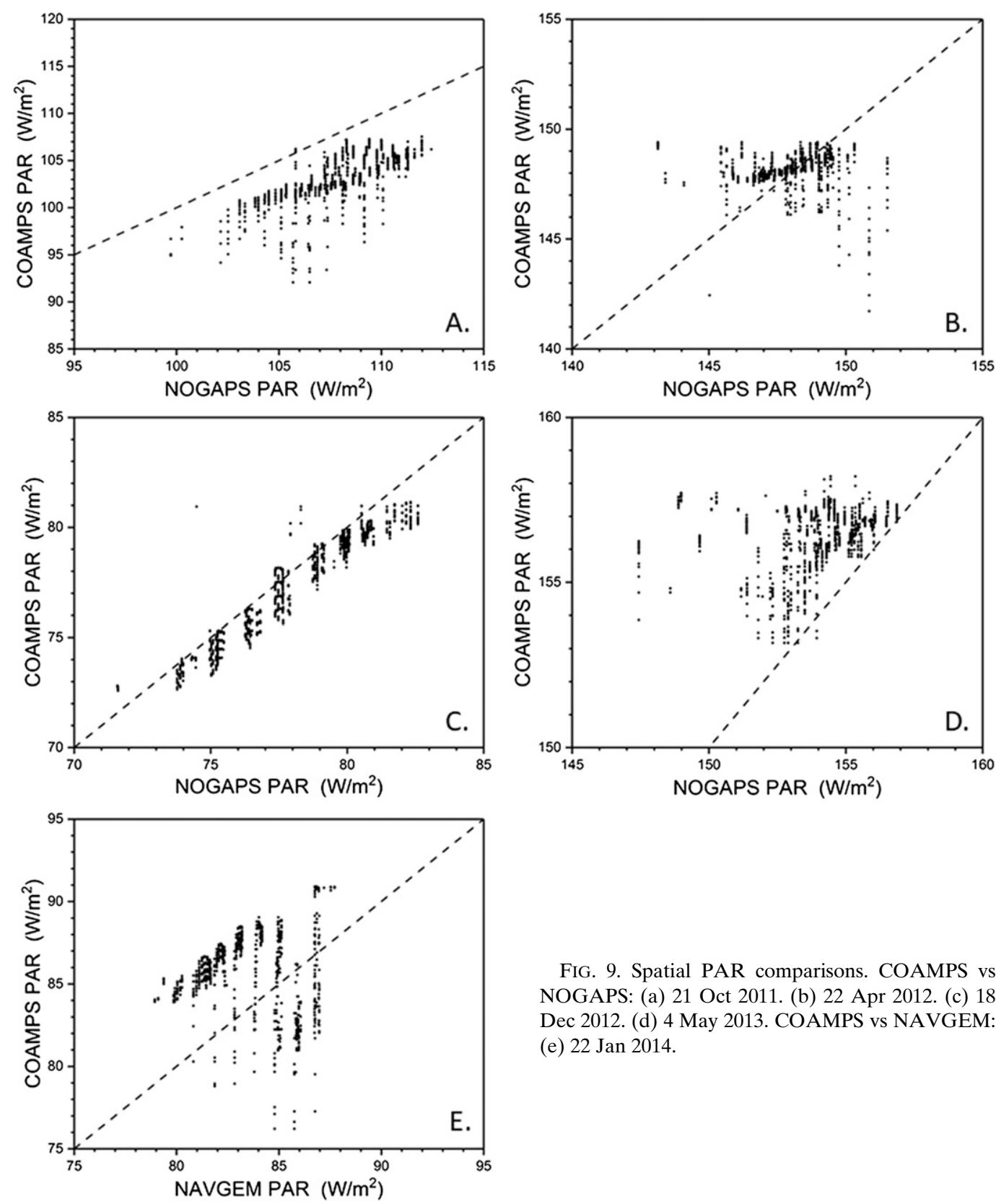

FIG. 9. Spatial PAR comparisons. COAMPS vs NOGAPS: (a) 21 Oct 2011. (b) 22 Apr 2012. (c) 18 Dec 2012. (d) 4 May 2013. COAMPS vs NAVGEM: (e) 22 Jan 2014.

we see this different pattern between the temporal and spatial comparisons.

Cloud coverage and aerosols impact the amount of PAR reaching the sea surface, its spatial distribution, and the fraction of diffuse radiation. Both satellite observations and model results show decreased cloud coverage over the Gulf of Mexico over a 25-yr period (Norris et al. 2016). Climate change could further alter cloud coverage (Collins et al. 2013), but the treatment of aerosols and clouds contribute the largest uncertainty in estimates of the downwelling shortwave radiation at

the surface (Zhang et al. 1995) and in Earth's changing energy budget by general circulation models used to predict future climate (Boucher et al. 2013). In fact, the uncertainty in the estimated radiative forcing attributed to aerosol-cloud interactions has not decreased over the past four Intergovernmental Panel on Climate Change (IPCC) cycles (Seinfeld et al. 2016).

The ratio of PAR to total irradiance can vary depending on cloudy or clear-sky conditions, because cloud transmittance in the 350-700-nm range is higher than over the entire solar spectrum (Baker and Frouin 1987). 

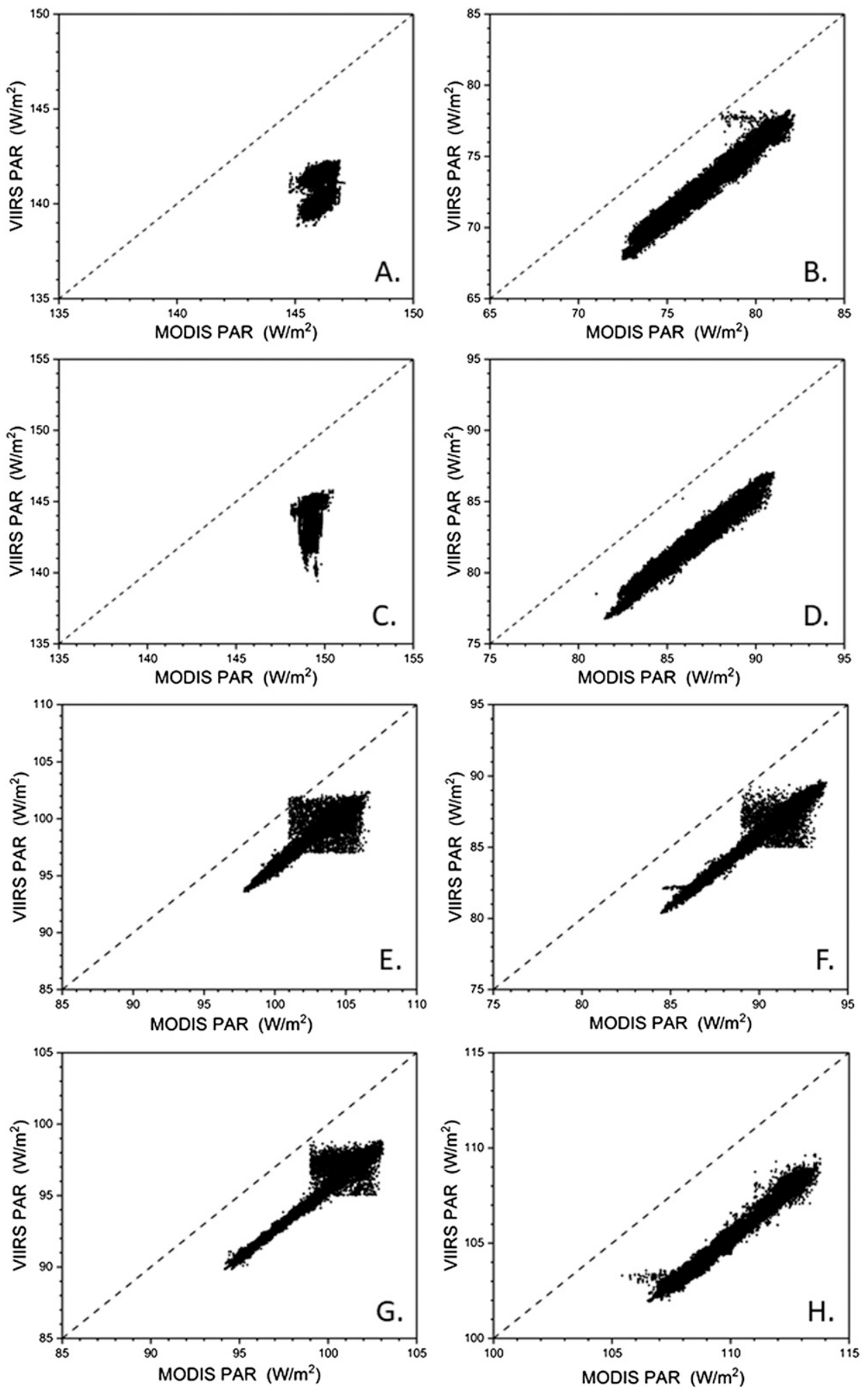

FIG. 10. Spatial PAR comparison, VIIRS vs MODIS. (a) 22 Apr 2012. (b) 18 Dec 2012. (c) 4 May 2013. (d) 22 Jan 2014. (e) 25 Oct 2014. (f) 27 Jan 2015. (g) 10 Feb 2016. (h) 25 Feb 2016. 
TABLE 5. Spatial PAR comparisons between satellite (MODIS, VIIRS), model (COAMPS, NOGAPS, NAVGEM), and in situ measurements from nine dates (see Table 1). Summary of results averaged over all nine dates (clear-sky conditions only).

\begin{tabular}{lc}
\hline \multicolumn{1}{c}{ Comparison result } & ARPD $(\%)$ \\
\hline NOGAPS > MODIS & 2.06 \\
COAMPS > MODIS & 0.87 \\
NOGAPS > VIIRS & 6.23 \\
COAMPS > VIIRS & 6.23 \\
MODIS > NAVGEM & 4.70 \\
NOGAPS > COAMPS & 0.82 \\
COAMPS > NAVGEM & 2.58 \\
VIIRS $>$ NAVGEM & 0.20 \\
MODIS > VIIRS & 4.33 \\
\hline
\end{tabular}

Higher photosynthetic efficiency has been observed under diffuse light conditions (Mercado et al. 2009). In addition, river discharge patterns in the future could be altered due to climate change, as a result of changing precipitation patterns (Sperna Weiland et al. 2012), which would lead to associated regional increases or decreases in nutrients and CDOM in coastal areas. Nutrients impact phytoplankton production and CDOM attenuates light, so both of these processes will alter the vertical distribution of PAR. In addition to estimating the correct magnitude of PAR, we must also correctly estimate the attenuation of PAR spatially, both horizontally and vertically with depth (Jolliff et al. 2012; Ko et al. 2016; Shulman et al. 2017). Thus, there are many interacting processes that affect water column and benthic light levels and primary production that are difficult to separate, but coupled biophysical ecological modeling provides one approach.

Some previous work has assessed the satellite ocean color PAR product as well as modeled shortwave radiation. Frouin et al. (2003) noted that the SeaWiFS PAR product (same algorithm used here) overestimated in situ values with a 5.3\% bias and a 15\% RMSE. Frouin and Pinker (1995) observed about 10\% PAR accuracies on daily time scales that decreased on longer (monthly) time scales. Laliberté et al. (2016), using the same PAR algorithm, observed a positive bias of $2 \%$ and a $20 \%$ RMSE for comparisons with in situ data at high northern latitudes.

Our uncertainty results for PAR from NOGAPS, COAMPS, and NAVGEM are similar to those reported for other radiative transfer models. Bouvet et al. (2002) reported an uncertainty of $5.2 \%$ when the radiative transfer model PARsat was validated against in situ mooring data. For NAVGEM, May et al. (2017) observed a mean absolute percent error (MAPE) of $55.6 \%$ when compared to in situ data. This value is not directly comparable with our calculated error statistic (ARPD), however, because MAPE is calculated using the absolute value of the errors whereas ours is not (thus, for ARPD, positive and negative errors "cancel" each other and the values are lower than MAPE). Except for the temporal comparison between COAMPS and MODIS, with an ARPD $=10.07 \%$, all other averaged model comparisons to in situ and satellite data yielded ARPD values between $0.15 \%$ and $6.23 \%$ (Tables 3, 5).

The atmospheric models used operationally by the Navy are updated periodically, as illustrated by the shift from NOGAPS to NAVGEM in 2013. However, we need to assess the performance of the new model to determine if it represents an improvement over previous models/versions. The work here is an attempt to do that in a limited fashion, for just the model PAR (shortwave radiation) product. Thus, our focus is to compare model PAR values (derived from shortwave radiation) to satellite-derived estimates and in situ measurements, and to intercompare multiple models. For the model intercomparison, we calculated ARPD values between the model pairs ranging from $0.82 \%$ to $5.57 \%$.

Currently, most coupled biophysical ocean models rely on gridded PAR (shortwave radiation) fields provided by an atmospheric model. One reason is that the model outputs are available over shorter time steps (e.g., every $3 \mathrm{~h}$ ) than what is available from the satellite ocean color imagery (one or several scenes available per day for a given area). In addition, the values on model grids are completely filled in through assimilation and interpolation techniques, whereas the satellite imagery can have missing values due to sunglint or clouds. Another limitation of imagery is that the PAR estimate at time of overpass is assumed to be representative of the whole day. Thus, on days with high cloud variability, the satellite estimate may not be representative of the rest of the day. However, polar-orbiting sensors with PAR capability may observe the same location several times during daytime at middle and high latitudes, and several satellite sensors are concurrently providing data, which should decrease uncertainties in daily PAR estimates. These shortcomings notwithstanding, satellite PAR will likely be assimilated into the models in the future. The main difficulty for NOGAPS, NAVGEM, or COAMPS to predict PAR more accurately is that the models lack the resolution as well as the full physics to make accurate cloud predictions and, to a lesser extent, the reflection from sea surface. This difficulty cannot be overcome without substantial research efforts. Although NAVGEM has replaced NOGAPS as the Navy operational global model, based 
on our limited comparisons it is not clear that NAVGEM provides improved results, in terms of shortwave radiation estimates. We have assessed both model and satellite variability relative to each other and to in situ data.

\section{Conclusions}

PAR values, which are required as input to biogeochemical physical models, are available from multiple sources, such as in situ observations, satellite imagery, and/or atmospheric models, and each source has intrinsic limitations. Prior to evaluating the impact of PAR variability on biogeochemical model results due to future environmental change, for example, it is important to understand the accuracy and the limitations of each potential PAR data source and how closely these values agree. We compare PAR values derived from ocean color satellite imagery to those from atmospheric models and in situ measurements in the Gulf of Mexico, to validate the imagery and models, and to assess PAR variability based on source. We performed spatial and temporal analyses covering multiple years and seasons, and clear/cloudy conditions.

Averaged over space or time, the relative errors in PAR between the six sources (two satellites, three atmospheric models, and in situ) are generally less than $5 \%-7 \%$ average relative percent difference, but they can vary up to $11 \%$. It is unlikely the relatively small $5 \%-7 \%$ differences will have a substantial impact on the overall outcome of biogeochemical models, although an error twice that magnitude, such as the observed $11 \%$ differences in some cases, could conceivably have an impact. However, these averages can also be misleading. The errors on a daily, pixel-by-pixel basis are much larger for all of the data sources, and may reach $50 \%$ in magnitude; thus, the averages can mask significant variations, as well as seasonal differences. In addition, because the daily, pixel-by-pixel PAR products are the ones more likely to be assimilated into biogeochemical models (rather than the spatial or temporal averages), the larger associated errors could have a potentially significant impact on model predictions over short temporal and small spatial scales. The biases, although relatively small, will affect the longer-term model predictions, and can have a larger impact as the length of the simulation increases, for "free-running," nonassimilative models. Thus, although the PAR errors are similar between the various data sources (satellite or atmospheric model), they can potentially impact biogeochemical model results, depending on the time and space scales of interest. In a companion paper, we are evaluating the sensitivity of primary production and hypoxia estimates from a biogeochemical model
(CGEM) to PAR variability, based on this study and potential climate change scenarios.

Acknowledgments. Funding for this work was provided by the U.S. Environmental Protection Agency (EPA) under an Inter-Agency Agreement to the Naval Research Laboratory (NRL), and by the NRL project, Integrated Coastal Bio-Optical Dynamics. Mr. C. MacDonald was funded under a U.S. Bureau of Ocean Energy Management (BOEM) contract to Sonoma Technology. We thank the Louisiana Universities Marine Consortium (LUMCON) for graciously providing in situ PAR data from their Terrebonne Bay and Southwest Pass long-term sampling stations. To access data used in this paper, please contact richard. gould@nrlssc.navy.mil.

\section{REFERENCES}

Baker, K. S., and R. Frouin, 1987: Relation between photosynthetically available radiation and total insolation at the ocean surface under clear skies. Limnol. Oceanogr., 32, 1370-1377, https://doi.org/10.4319/lo.1987.32.6.1370.

Bélanger, S., M. Babin, and J. É. Tremblay, 2013: Increasing cloudiness in Arctic damps the increase in phytoplankton primary production due to sea ice receding. Biogeosciences, 10, 4087-4101, https://doi.org/10.5194/bg-10-4087-2013.

Boucher, O., and Coauthors, 2013: Clouds and aerosols. Climate Change 2013: The Physical Science Basis, T. F. Stocker et al., Eds., Cambridge University Press, 571-657.

Bouvet, M., N. Hoepffner, and M. D. Dowell, 2002: Parameterization of a spectral solar irradiance model for the global ocean using multiple satellite sensors. J. Geophys. Res., 107, 3215, https://doi.org/10.1029/2001JC001126.

Bulgarelli, B., and G. Zibordi, 2018a: On the detectability of adjacency effects in ocean color remote sensing of mid-latitude coastal environments by SeaWiFS, MODIS-A, MERIS, OLCI, OLI and MSI. Remote Sens. Environ., 209, 423-438, https://doi.org/10.1016/j.rse.2017.12.021.

$\longrightarrow$, and $-2018 \mathrm{~b}$ : Seasonal impact of adjacency effects on ocean color radiometry at the AAOT validation site. IEEE Geosci. Remote Sens. Lett., 15, 488-492, https://doi.org/10.1109/ LGRS.2017.2781900.

Campbell, J. W., and T. Aarup, 1989: Photosynthetically available radiation at high latitudes. Limnol. Oceanogr., 34, 1490-1499, https://doi.org/10.4319/lo.1989.34.8.1490.

—, and Coauthors, 2002: Comparison of algorithms for estimating ocean primary production from surface chlorophyll, temperature, and irradiance. Global Biogeochem. Cycles, 16, 1035, https://doi.org/10.1029/2001GB001444.

Cao, C., F. J. D. Luccia, X. Xiong, R. Wolfe, and F. Weng, 2014: Early on-orbit performance of the Visible Infrared Imaging Radiometer Suite onboard the Suomi National Polar-Orbiting Partnership (S-NPP) satellite. IEEE Trans. Geosci. Remote Sens., 52, 1142-1156, https://doi.org/10.1109/ TGRS.2013.2247768.

Carr, M.-E., and Coauthors, 2006: A comparison of global estimates of marine primary production from ocean color. Deep-Sea Res. II, 53, 741-770, https://doi.org/10.1016/ j.dsr2.2006.01.028. 
Clough, S., M. W. Shephard, E. J. Mlawer, J. S. Delamere, M. J. Iacono, K. Cady-Pereira, S. Boukabara, and P. D. Brown, 2005: Atmospheric radiative transfer modeling: A summary of the AER codes. J. Quant. Spectrosc. Radiat. Transf., 91, 233-244, https://doi.org/10.1016/j.jqsrt.2004.05.058.

Collins, M., and Coauthors, 2013: Long-term climate change: Projections, commitments and irreversibility. Climate Change 2013: The Physical Science Basis, T. F. Stocker et al., Eds., Cambridge University Press, 1029-1136.

Davies, R., 1982: Documentation of the solar radiation parameterization in the GLAS climate model. NASA Tech. Memo 83961, 57 pp., https://ntrs.nasa.gov/archive/nasa/casi.ntrs.nasa.gov/ 19820022903.pdf.

Edwards, A. M., D. G. Wright, and T. Platt, 2004: Biological heating effect of a band of phytoplankton. J. Mar. Syst., 49, 89-103, https://doi.org/10.1016/j.jmarsys.2003.05.011.

Friedrichs, M. A. M., and Coauthors, 2009: Assessing the uncertainties of model estimates of primary productivity in the tropical Pacific Ocean. J. Mar. Syst., 76, 113-133, https:// doi.org/10.1016/j.jmarsys.2008.05.010.

Frouin, R., and R. T. Pinker, 1995: Estimating photosynthetically active radiation (PAR) at the earth's surface from satellite observations. Remote Sens. Environ., 51, 98-107, https:// doi.org/10.1016/0034-4257(94)00068-X.

, and H. Murakami, 2007: Estimating photosynthetically available radiation at the ocean surface from ADEOS-II global imager data. J. Oceanogr., 63, 493-503, https://doi.org/ 10.1007/s10872-007-0044-3.

— B. A. Franz, and P. J. Werdell, 2003: The SeaWiFS PAR Product. Algorithm Updates for the Fourth SeaWiFS Data Reprocessing, NASA Tech. Memo. 2003-206892, Vol. 22, 46-50 pp., https://oceancolor.gsfc.nasa.gov/docs/technical/ seawifs_reports/postlaunch/PLVol22.pdf.

- J. McPherson, K. Ueyoshi, and B. A. Franz, 2012: A time series of photosynthetically available radiation at the ocean surface from SeaWiFS and MODIS data. Proc. SPIE, 8525, 852519, https://doi.org/10.1117/12.981264.

, and Coauthors, 2018: Satellite radiation products for ocean biology and biogeochemistry: Needs, state-of-the-art, gaps, development priorities, and opportunities. Front. Mar. Sci., 5, https://doi.org/10.3389/fmars.2018.00003.

Gildor, H., A. H. Sobel, M. A. Cane, and R. N. Sambrotto, 2003: A role for ocean biota in tropical intraseasonal atmospheric variability. Geophys. Res. Lett., 30, 1460, https://doi.org/ 10.1029/2002GL016759.

Gould, R. W., S. C. McCarthy, E. Coelho, I. Shulman, and J. G. Richman, 2014: Combining satellite ocean color and hydrodynamic model uncertainties in bio-optical forecasts. J. Appl. Remote Sens., 8, 083652, https://doi.org/10.1117/ 1.JRS.8.083652.

Harshvardhan, R. Davies, D. A. Randall, and T. G. Corsetti, 1987: A fast radiation parameterization for atmospheric circulation models. J. Geophys. Res., 92, 1009-1016, https://doi.org/10.1029/ JD092iD01p01009.

Hodur, R. M., 1997: The Naval Research Laboratory's coupled ocean/atmosphere mesoscale prediction system (COAMPS). Mon. Wea. Rev., 125, 1414-1430, https://doi.org/10.1175/ 1520-0493(1997)125<1414:TNRLSC $>2.0 . C O ; 2$.

Hogan, T. F., and T. E. Rosmond, 1991: The description of the Navy Operational Global Atmospheric Prediction System's spectral forecast model. Mon. Wea. Rev., 119, 1786-1815, https://doi.org/10.1175/1520-0493(1991)119<1786:TDOTNO> 2.0. $\mathrm{CO} ; 2$
— , and Coauthors, 2014: The Navy Global Environmental Model. Oceanography, 27, 116-125, https://doi.org/10.5670/ oceanog.2014.73.

Jitts, H., A. Morel, and Y. Saijo, 1976: The relation of oceanic primary production to available photosynthetic irradiance. Mar. Freshwater Res., 27, 441-454, https://doi.org/10.1071/MF9760441.

Jolliff, J. K., T. A. Smith, C. N. Barron, S. deRada, S. C. Anderson, R. W. Gould, and R. A. Arnone, 2012: The impact of coastal phytoplankton blooms on ocean-atmosphere thermal energy exchange: Evidence from a two-way coupled numerical modeling system. Geophys. Res. Lett., 39, L24607, https:// doi.org/10.1029/2012GL053634.

Ko, D., R. Gould, B. Penta, and J. Lehrter, 2016: Impact of satellite remote sensing data on simulations of coastal circulation and hypoxia on the Louisiana continental shelf. Remote Sens., 8, 435, https://doi.org/10.3390/rs8050435.

Laliberté, J., S. Bélanger, and R. Frouin, 2016: Evaluation of satellite-based algorithms to estimate photosynthetically available radiation (PAR) reaching the ocean surface at high northern latitudes. Remote Sens. Environ., 184, 199-211, https://doi.org/10.1016/j.rse.2016.06.014.

Lehrter, J. C., D. S. Ko, L. L. Lowe, and B. Penta, 2017: Predicted effects of climate change on northern Gulf of Mexico hypoxia. Modeling Coastal Hypoxia, D. Justic et al., Eds., Springer, 173-214.

Lewis, M. R., J. J. Cullen, and T. Platt, 1983: Phytoplankton and thermal structure in the upper ocean: Consequences of nonuniformity in chlorophyll profile. J. Geophys. Res., 88, 25652570, https://doi.org/10.1029/JC088iC04p02565.

Long, S., S. Humphries, and P. G. Falkowski, 1994: Photoinhibition of photosynthesis in nature. Annu. Rev. Plant Biol., 45, 633662, https://doi.org/10.1146/annurev.pp.45.060194.003221.

MacDonald, C. P., A. E. Ray, P. T. Roberts, C. A. Knoderer, L. Bariteau, C. W. Fairall, W. J. Gibson, and J. E. Hare, 2013: Meteorological and wave measurements for improving meteorological and air quality modeling. OCS Study BOEM 2013-01110, 102 pp., https://www.boem.gov/ESPIS/5/5287.pdf.

Martin, P. J., 2000: Description of the Navy Coastal Ocean Model version 1.0. Naval Research Laboratory Tech. Rep. NRL/FR/ 7322-0-9962, 42 pp., https://apps.dtic.mil/dtic/tr/fulltext/u2/ a387444.pdf.

May, J. C., C. Rowley, and C. N. Barron, 2017: NFLUX satellitebased surface radiative heat fluxes. Part II: Gridded products. J. Appl. Meteor. Climatol., 56, 1043-1057, https://doi.org/ 10.1175/JAMC-D-16-0283.1.

Mercado, L. M., N. Bellouin, S. Sitch, O. Boucher, C. Huntingford, M. Wild, and P. M. Cox, 2009: Impact of changes in diffuse radiation on the global land carbon sink. Nature, 458, 1014 1017, https://doi.org/10.1038/nature07949.

Morel, A., and R. C. Smith, 1974: Relation between total quanta and total energy for aquatic photosynthesis. Limnol. Oceanogr., 19, 591-600, https://doi.org/10.4319/lo.1974.19.4.0591.

Nakamoto, S., S. P. Kumar, J. Oberhuber, K. Muneyama, and R. Frouin, 2000: Chlorophyll modulation of sea surface temperature in the Arabian Sea in a mixed-layer isopycnal general circulation model. Geophys. Res. Lett., 27, 747-750, https:// doi.org/10.1029/1999GL002371.

Nelson, J. R., 1993: Rates and possible mechanism of lightdependent degradation of pigments in detritus derived from phytoplankton. J. Mar. Res., 51, 155-179, https://doi.org/ 10.1357/0022240933223837.

Norris, J. R., R. J. Allen, A. T. Evan, M. D. Zelinka, C. W. O'Dell, and S. A. Klein, 2016: Evidence for climate change in the 
satellite cloud record. Nature, 536, 72-75, https://doi.org/10.1038/ nature18273.

Papaioannou, G., N. Papanikolaou, and D. Retalis, 1993: Relationships of photosynthetically active radiation and shortwave irradiance. Theor. Appl. Climatol., 48, 23-27, https://doi.org/ 10.1007/BF00864910.

Pinker, R., and I. Laszlo, 1992: Global distribution of photosynthetically active radiation as observed from satellites J. Climate, 5, 56-65, https://doi.org/10.1175/1520-0442(1992) 005<0056:GDOPAR > 2.0.CO;2.

Platt, T., 1986: Primary production of the ocean water column as a function of surface light intensity: Algorithms for remote sensing. Deep-Sea Res., 33A, 149-163, https://doi.org/10.1016/ 0198-0149(86)90115-9.

— C. C. Gallegos, and W. Harrison, 1980: Photoinhibition of photosynthesis in natural assemblages of marine phytoplankton. J. Mar. Res., 38, 687-701.

Rosmond, T. E., 1992: The design and testing of the Navy Operational Global Atmospheric Prediction System. Wea. Forecasting, 7, 262-272, https://doi.org/10.1175/1520-0434(1992) 007<0262:TDATOT $>2.0 . \mathrm{CO} ; 2$.

__ J. Jeixeira, M. Peng, T. F. Hogan, and R. Pauley, 2002: Navy Operational Global Atmospheric Prediction System (NOGAPS): Forcing for ocean models. Oceanography, 15, 99-108, https://doi.org/10.5670/oceanog.2002.40.

Sathyendranath, S., A. D. Gouveia, S. R. Shetye, P. Ravindran, and T. Platt, 1991: Biological control of surface temperature in the Arabian Sea. Nature, 349, 54-56, https://doi.org/10.1038/ 349054a0.

Saux Picart, S., S. Sathyendranath, M. Dowell, T. Moore, and T. Platt, 2014: Remote sensing of assimilation number for marine phytoplankton. Remote Sens. Environ., 146, 87-96, https://doi.org/10.1016/j.rse.2013.10.032.

Seinfeld, J. H., and Coauthors, 2016: Improving our fundamental understanding of the role of aerosol-cloud interactions in the climate system. Proc. Natl. Acad. Sci. USA, 113, 5781-5790, https://doi.org/10.1073/pnas.1514043113.

Shank, G. C., A. Evans, Y. Yamashita, and R. Jaffé, 2011: Solar radiation-enhanced dissolution of particulate organic matter from coastal marine sediments. Limnol. Oceanogr., 56, 577588, https://doi.org/10.4319/lo.2011.56.2.0577.
Shulman, I., S. Frolov, S. Anderson, B. Penta, R. Gould, P. Sakalaukus, and S. Ladner, 2013: Impact of bio-optical data assimilation on short-term coupled physical, bio-optical model predictions. J. Geophys. Res. Oceans, 118, 2215-2230, https:// doi.org/10.1002/jgrc.20177.

—, R. W. Gould, S. Anderson, and P. Sakalaukus, 2017: Impact of errors in short wave radiation and its attenuation on modeled upper ocean heat content. J. Appl. Remote Sens., 11, 032402, https://doi.org/10.1117/1.JRS.11.032402.

Simonot, J.-Y., E. Dollinger, and H. Le Treut, 1988: Thermodynamicbiological-optical coupling in the oceanic mixed layer. J. Geophys. Res., 93, 8193-8202, https://doi.org/10.1029/ JC093iC07p08193.

Somayajula, S. A., E. Devred, S. Bélanger, D. Antoine, V. Vellucci, and M. Babin, 2018: Evaluation of sea-surface photosynthetically available radiation algorithms under various sky conditions and solar elevations. Appl. Opt., 57, 3088-3105, https:// doi.org/10.1364/AO.57.003088.

Sperna Weiland, F., L. Van Beek, J. Kwadijk, and M. Bierkens, 2012: Global patterns of change in discharge regimes for 2100. Hydrol. Earth Syst. Sci., 16, 1047-1062, https://doi.org/10.5194/ hess-16-1047-2012.

Wallcraft, A. J., A. B. Kara, H. E. Hurlburt, E. P. Chassignet, and G. H. Halliwell, 2008: Value of bulk heat flux parameterizations for ocean SST prediction. J. Mar. Syst., 74, 241-258, https://doi.org/10.1016/j.jmarsys.2008.01.009.

Zaneveld, J. R. V., J. C. Kitchen, and H. Pak, 1981: The influence of optical water type on the heating rate of a constant depth mixed layer. J. Geophys. Res., 86, 6426-6428, https://doi.org/ 10.1029/JC086iC07p06426.

Zhang, Y., M. Liu, B. Qin, and S. Feng, 2009: Photochemical degradation of chromophoric-dissolved organic matter exposed to simulated UV-B and natural solar radiation. Hydrobiologia, 627, 159-168, https://doi.org/10.1007/ s10750-009-9722-z.

Zhang, Y.-C., W. B. Rossow, and A. A. Lacis, 1995: Calculation of surface and top of atmosphere radiative fluxes from physical quantities based on ISCCP data sets: 1. Method and sensitivity to input data uncertainties. J. Geophys. Res., 100, 1149-1165, https://doi.org/10.1029/ 94JD02747. 